Special Section: Soil-Plant-

Atmosphere Continuum

Giorgio Cassiani*

Nadia Ursino

Rita Deiana

Giulio Vignoli

Jacopo Boaga

Matteo Rossi

Maria Teresa Perri

Michael Blaschek

Rainer Duttmann

Swen Meyer

Ralf Ludwig

Antonino Soddu

Peter Dietrich

Ulrike Werban

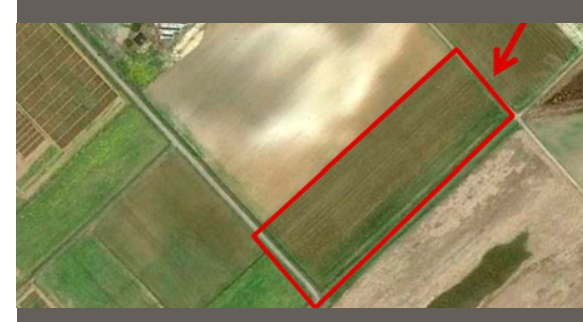

This paper presents the results of seasonal monitoring and irrigation tests in a semiarid region of Sardinia, using mainly electromagnetic induction and electrical resistivity tomography time lapse monitoring. The vegetation has a significant impact on the soil moisture dynamics, changing infiltration and evapotranspiration patterns.

G. Cassiani, J. Boaga, M. Rossi, and M. T. Perri, Dipartimento di Geoscienze, Università degli Studi di Padova, Via Gradenigo 6, 35131 Padova, Italy; R. Deiana, Dipartimento di Beni Culturali, Università Deiana, Dipartimento di Beni Culturali, Università
degli Studi di Padova, Piazza Capitaniato 7, 35139, degli Studi di Padova, Piazza Capitaniato 7, 35139,
Padova, Italy; N. Ursino, Dipartimento ICEA, Università degli Studi di Padova, Via Loredan 20, 35131 Padova, Italy; G. Vignoli, King Fahd Univ. of Petroleum and Minerals, Earth Sciences Dep., 31261 Dhahran, Saudi Arabia; currently Department of Geoscience, HydroGeophysics Group, Aarhus University, Aarhus, Denmark; M. Blaschek and R. Duttmann, Institute for Landscape Ecology and Geoinformation, Dep. of Geography, Univ. of Kiel, Ludewig-Meyn-Strasse 14, 24098 Kiel, Germany; S. Meyer and R. Ludwig, Dep. of Geography, Univ. of Munich, Luisenstr. 37, 80333 Munich, Germany; A. Soddu, AGRIS Sardegna, Viale Trieste 111,09100 Cagliari, Italy; P. Dietrich and U. Werban, UFZ - HelmholtzCentre for Environmental Research, Dept. Monitoring and Exploration Technologies, Permoserstr. 15, Leipzig, Germany. *Corresponding author (giorgio.cassiani@unipd.it).

Vadose Zone J.

doi:10.2136/vzj2011.0195

Received 16 Dec. 2011.

(C) Soil Science Society of America

5585 Guilford Rd., Madison, WI 53711 USA. All rights reserved. No part of this periodical may be reproduced or transmitted in any form or by any means, electronic or mechanical, including photocopying, recording, or any information storage and retrieval system, without permission in writing from the publisher.

\section{Noninvasive Monitoring of Soil Static Characteristics and Dynamic States: A Case Study Highlighting Vegetation Effects on Agricultural Land}

In this paper we present the results of seasonal monitoring and irrigation tests performed on an experimental farm in a semiarid region of Southern Sardinia. The goal of the study is to understand the soil-vegetation interactions and how they can affect the soil water balance, particularly in view of possible climatic changes. We used long-term electromagnetic induction (EMI) time lapse monitoring and short-term irrigation experiments monitored using electrical resistivity tomography (ERT) and EMI, supported by time domain reflectometry (TDR) soil moisture measurements. Mapping of natural $\psi$-ray emission, texture analysis, and laboratory calibration of an electrical constitutive relationship on soil samples complete the dataset. We observe that the growth of vegetation, with the associated below-ground allocation of biomass, has a significant impact on the soil moisture dynamics. It is well known that vegetation extracts a large amount of water from the soil particularly during summer, but it also reduces evaporation by shadowing the soil surface. Vegetation represents a screen for rainfall and prevents light rainfall infiltration but enhances the wetting process by facilitating the infiltration and the ground water recharge. In many cases, the vegetation creates a positive feedback system. In our study, these mechanisms are well highlighted by the use of noninvasive techniques that provide data at the scale and resolution necessary to understand the hydrological processes of the topsoil, also in their lateral and depth spatial variability. Unlike remote sensing techniques, noninvasive geophysics penetrates the soil subsurface and can effectively image moisture content in the root zone. We also developed a simple conceptual model capable of representing the vegetation-soil interaction with a simple enough parameterization that can be fulfilled by measurements of a noninvasive nature, available at a large scale and evidences possible relevant developments of our research.

Abbreviations: EMI, electromagnetic induction; ERT, electrical resistivity tomography; TDR, time domain reflectometry.

Upscaling knowledge on soil moisture dynamics and vegetation growth into the soil from the small scale of a single root and soil structure (see e.g., Javaux et al., 2008) to the larger field scale is still a partially unexplored and challenging task that has relevant implication in the interdisciplinary fields of ecohydrology and geoecohydrology. The form of root growth is an important aspect of the study of vegetation in arid areas, but the plant root system is not easily accessible and far less studied. The structure and function of roots are expected to evolve for optimal uptake of water leading eventually to competition among different species (Cody, 1986 and reference therein).

In terms of coupled dynamics, the soil supports the plant growth and, conversely, the below-ground architecture of plants can affect the soil structure and thus its physical characteristics having an indirect impact on the subsurface water fluxes. Soil moisture balance and biomass balance are strongly interconnected due to their two-way interaction and the positive and negative feedbacks that take place between the dynamics of water and the vegetation growth.

Preferential infiltration and soil moisture redistribution have been indicated as the two major processes influencing the establishment and persistence of spontaneous vegetation cover and vegetation patterns in arid and semiarid land (HilleRisLambers et al., 2001; Rietkerk et al., 2002). Furthermore, Ursino (2007) demonstrated that the plant survival strategy determines which of the above mentioned hydrological processes is more important. Vegetation that consumes less water relies more on preferential infiltration for surviving under scarce mean annual rainfall and leads to a 
scenario where more soil moisture is lost due to runoff and leakage (Ursino, 2005, 2007, 2009).

Noninvasive techniques can play a key role in the hydrological investigation of the near surface, as they provide spatially extensive imaging that complements the more traditional hydrological point measurements (e.g., Vereecken et al., 2006). A number of studies have appeared in the recent literature, particularly focused on ground-penetrating radar (GPR) and ERT. The use of these techniques has been increasingly focused on their ability to measure, albeit indirectly, changes in moisture content (e.g., Binley et al., 1996; Michot et al., 2003; Strobbia and Cassiani, 2007; Deiana et al., 2008) and solute concentration (e.g., Cassiani et al., 2006) by conducting time-lapse measurements. Recently, ERT has also been used to image the root zone geometry, with some degree of success (Werban et al., 2008; al Hagrey and Petersen, 2011). Frequency-Domain EMI is also widely used in soil mapping, to determine soil salinity (e.g., Corwin and Lesch, 2005), subsurface morphology (e.g., Comas et al., 2004), and texture (e.g., Jung et al., 2005; Triantafilis and Lesch, 2005) thanks to its noncontact capability of producing georeferenced data quickly and inexpensively. Applications of time-lapse EMI to determine soil moisture changes and study soil hydrological processes have been limited to date (Kachanoski et al., 1988; Sheets and Hendrickx, 1995; Abdu et al., 2008; Robinson et al., 2009) and deserve further attention (Robinson et al., 2008).

On the other hand, suitable modeling techniques are necessary to exploit the information content of field data and answer critical questions about basic mechanisms. Flow through porous media have been extensively investigated on the base of the continuum theory, by formulating the soil moisture balance equations at the scale of the representative elementary volume (Bear, 1972; Richards, 1931). The growing interest in interdisciplinary sciences that consider the spatial and temporal evolution of different species conditioned to the hydrology of the ecosystem where the growth lead in the last 10 to $15 \mathrm{yr}$ to the frequent adoption of minimal bucket models formulated at a much larger scale for the soil moisture balance instead of the more rigorous approach based on the continuum theory. Evaporation evapotranspiration, infiltration, lateral subsurface flow, and leakage are the building blocks of the soil water balance at the field scale, and they are all influenced by vegetation roots and soil properties. (Eagleson, 2002; Nuttle, 2002; Porporato and Rodriguez-Iturbe, 2004).

The Mediterranean ecosystem is characterized by dry summer and wet winter producing water stress conditions for the vegetation that grows during summer. Grasses that are characterized by high water demand during winter and spring are more drought adapted, even though there is anyway a lag time between soil moisture accumulation during the rainy season and soil moisture use during the growing season. Soil moisture storage and thus soil moisture availability during the growing season depends on the partitioning between infiltration and runoff, the flow field within the root zone and the depth of the root zone that represents the volume where water is stored. Minimal models based on soil moisture and biomass balance (such as the one that will be introduced here), have a steady state solution that does not depend on the depth of the root zone when the hydrologic forcing (rainfall and evapotranspiration) is set at its constant annual average. But when the time lag between water storage and water release comes into play, the root zone depth becomes crucial for the soil moisture balance and thus for the survival of selected vegetation species. At an intra-seasonal time scale for random rainfall pulses the water balance and the optimum root depth are governed by the rainfall frequency and intensity (Milly, 1993; Porporato et al., 2004; Guswa, 2008, 2010). At the catchment scale of our experiment, the focus switches from species survival and adaptation to other hot topics related to land and water management (Jackson et al., 2009). On an average annual basis, major issues concerning the connectivity of the soil moisture paths above ground through overland flow and below ground through lateral flow and the connectivity of the soil surface with the water table should be raised to clarify how annual precipitation, evapotranspiration and water yield are altered by a land use change. In a specific ecohydrological context the interrelation between infiltration, plant growth and water yield depends on biological variables (leaf area index, rooting depth, and seasonality of plant activity), climate and soil texture (Huxman et al., 2005; Newman et al., 2006). The soil structure is often related to vegetation growth and to the soil heterogeneity that the vegetation growth transfer on the soil structure (e.g., Flury et al., 1994).

In this paper we address, at least partly, the general question of what could be the impact of vegetation and particularly of root architecture on soil properties and indirectly on the water cycle, according to the experimental evidence collected via noninvasive techniques. In more in detail, we discuss the interconnection between soil moisture paths, soil moisture path connectivity and vegetation cover. We do this by comparing noninvasive field observations with the results of a very simple conceptual model. The experimental study was conducted at an agricultural experimental farm located in Sardinia, Italy, as part of the part of the EU-FP7 CLIMB project (Ludwig et al., 2010), focused on the analysis of climate change impacts on the hydrology of Mediterranean basins. The main goal of the experimental activities within CLIMB are to collect information about the hydrologic behavior of Mediterranean catchments, ranging from the small soil profile scale to the larger catchment scale.

The interpretation of collected data has been supported by an ecohydrological minimal model, incorporating knowledge on the relevant feedbacks between root architecture and dynamic water balance in cultivated soils. 


\section{Site Description}

The study site is located at the San Michele farm in the Rio Mannu Catchment (Southern Sardinia). The basin ranges in elevation from 62 to $842 \mathrm{~m}$ asl with an average of $295.5 \mathrm{~m}$ asl. The basin is mainly covered by agriculture fields and grassland, while only a small percentage of its area is occupied by forests in the southeast of the basin. The farm area has a gentle topography and is part of the Campidano plain. The soils in the area are brown soils, regosols and vertisoils or marls, with outcrops of sandstones and conglomerates. The floodplain is characterized by alluvial soils, predominantly gravelly or sandy gravel. The yearly mean total precipitation in the farm area is about $500 \mathrm{~mm}$ with an estimated mean runoff of about $200 \mathrm{~mm}$. The hydrological regime is characterized by wet periods from October to April, where more than 90\% of the rainfall is accumulated, and very dry summers (May-September). The yearly average temperature is $16^{\circ} \mathrm{C}$. Groundwater is thought to provide a negligible contribution to the streamflow. The San Michele farm is an agronomic research field covering an area of $4.36 \mathrm{~km}^{2}$ and managed by AGRIS, a research agency of Regione Autonoma della Sardegna government. Part of the Azienda $\left(\sim 2 \mathrm{~km}^{2}\right)$ is located in a hilly area with Maquis shrubland vegetation that is also a center of wildlife animal restocking. In the northeastern part, the Azienda is delimited by the San Michele hill. At the bottom of this hill, the Rio Flumineddu joins the Rio Mannu. The farm has been used for decades to investigate agricultural genetics for a more efficient farming of durum wheat (Triticum turgidum L.) in climatic conditions with frequent drought periods, such as the Sardinian ones. Today, the experimental agricultural fields are destined to open-field Mediterranean cultivations, particularly important for the economy of the island.

The soil in the farm is characterized by silty-sandy agricultural soil overlying a formation with abundant calcium carbonate nodules. A plow layer about $30 \mathrm{~cm}$ thick is maintained across the site by land preparation each year, irrespective of the soil being used for cultivation. No soil pan layer is present, thanks to the careful cultivation practices, including periodic deep plowing. Figure 1 shows a satellite view of the San Michele farm evidencing the areas where measurements have taken place. Traditional and noninvasive methods have been applied to monitor changing moisture content conditions on selected fields since 2009.

In two field campaigns (October 2010 and March 2011) about 300 soil samples from three depths $(0-30,30-60$ and $60-90 \mathrm{~cm})$ were collected over the Rio Mannu catchment. Forty-three of these samples from 0-30 cm depth were taken over Field 21. The corresponding grain size distribution is summarized in Table 1 , while interpolated maps of clay, silt and sand weight percentages and $\mathrm{CaCO}_{3}$ percentages are shown in Fig. 2. The spatial variations of grain size fractions is consistent with the geomorphologic features of the area: for example, sand prevails in the southern part of Field 21 , in correspondence of the original bed of the creek flowing from east (see Fig. 1). However these variations are subtle, with all fractions having ranges around $10 \%$.

In October 2010 a collaboration between the EU FP7 projects CLIMB and iSOIL (Werban et al., 2010) brought a UFZ field crew to the field site and allowed, among other things, for a rapid mapping of natural $\gamma$-ray emission over nearly the entire farm. The most prominent evidence from this $\gamma$-ray survey is a strong correlation

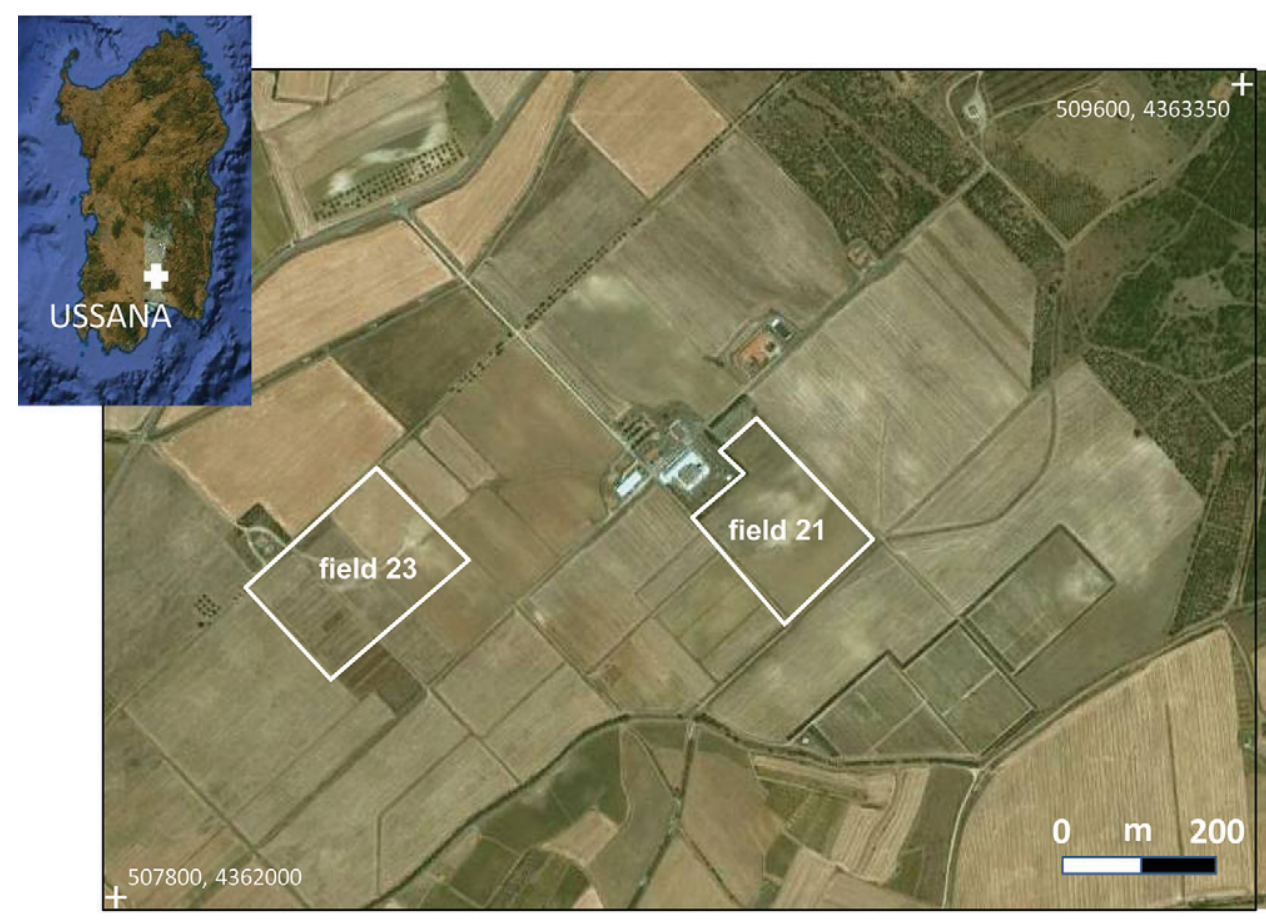

Fig. 1. Satellite view of the San Michele farm in Ussana, near Cagliari, Sardinia. Coordinates are UTM 32. (Image source: Google Earth).

Table 1. Results of grain size analysis on the San Michele farm (Ussana, Cagliari, Sardinia).

\begin{tabular}{|c|c|c|c|c|c|}
\hline & Min. & Max. & Median & Mean & SD \\
\hline Clay, \% (w/w) & 21.43 & 44.52 & 34.43 & 33.50 & 5.76 \\
\hline Silt, \% (w/w) & 19.08 & 34.87 & 25.55 & 26.00 & 3.89 \\
\hline Sand, \% (w/w) & 31.02 & 55.31 & 36.70 & 40.51 & 7.26 \\
\hline $\mathrm{C}_{\text {org }}, \%(\mathrm{w} / \mathrm{w})$ & 0.52 & 1.19 & 0.79 & 0.83 & 0.21 \\
\hline
\end{tabular}


between low total dose rate and a whiter soil color, which in turn is associated to a high calcium carbonate content (Fig. 2), derived from erosion of calcite nodules (Fig. 3). Note that the different soil color is visible in satellite images (e.g., in Fig. 3) solely because Field 21 was maintained free of vegetation for long periods as part of a remote sensing ground-truthing experiment.

\section{Irrigation Experiment: Results and Discussion}

In May 2010, a controlled irrigation experiment was undertaken on Field 23 (see map in Fig. 1) where the eastern plot was cultivated with alfalfa (Medicago sativa L.) even though several other invasive species coexisted with it at the time of the experiment. The western plot was left bare, but few spontaneously growing species survived there. A satellite view of Field 23 at the time of the experiment is shown in Fig. 4a, from which it is apparent how the vegetation
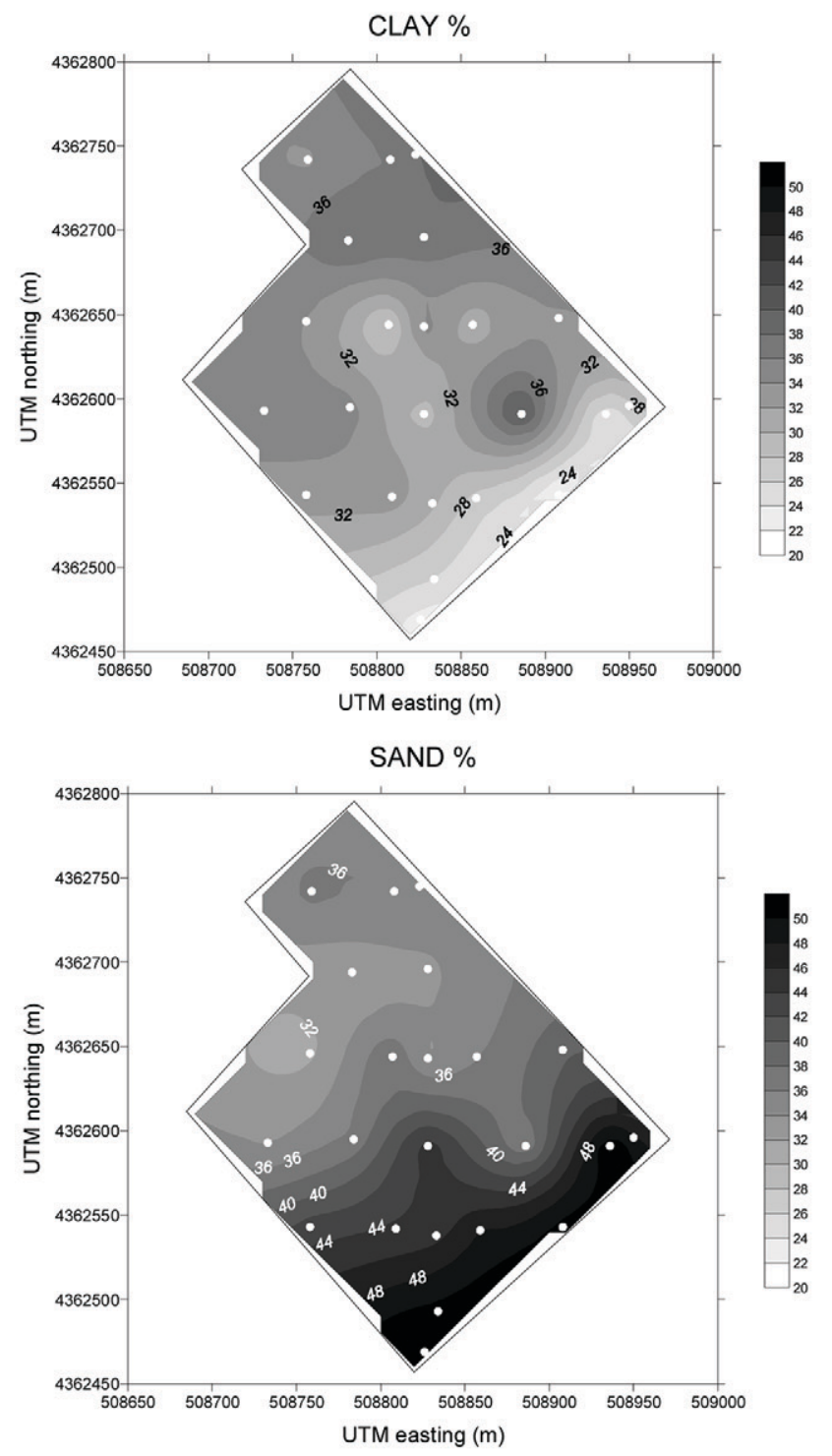

cover is substantially different in the two plots separated by a dirt road. The vegetation density can also be appreciated by the photographs in Fig. 4c and 4d.

Figure 5 shows the typical root architecture of the different species that cover the two plots. The vegetation in the cultivated site is uniform with high density and preferential allocation of biomass above ground; the roots are shallow. This fact does not allow indication, though, that the roots are not able to extract water from deeper in the soil profile via suction. On the contrary, the vegetation cover in the bare soil appears sparse above ground but the allocation of biomass is, in this case, preferential below ground. Spontaneous vegetation growing in the bare soil presents deep roots that spread both vertically and horizontally.

No difference in soil texture or color is apparent between the two plots, as evidenced in Fig. 4b, where we show the natural $\gamma$
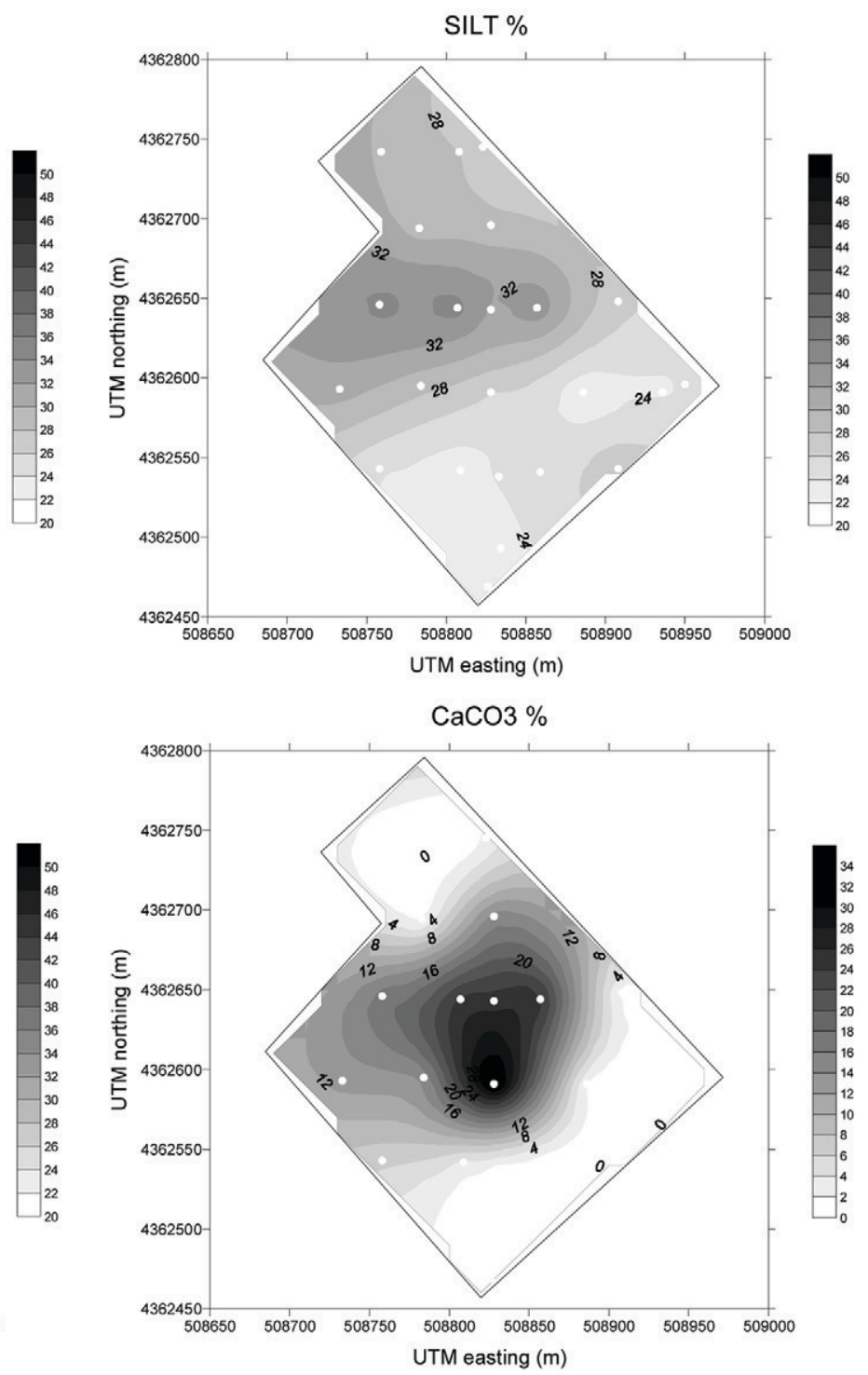

Fig. 2. Interpolated grain size percentages and carbonate content on Field 21. 
total dose rate $(\mathrm{nG} / \mathrm{h})$
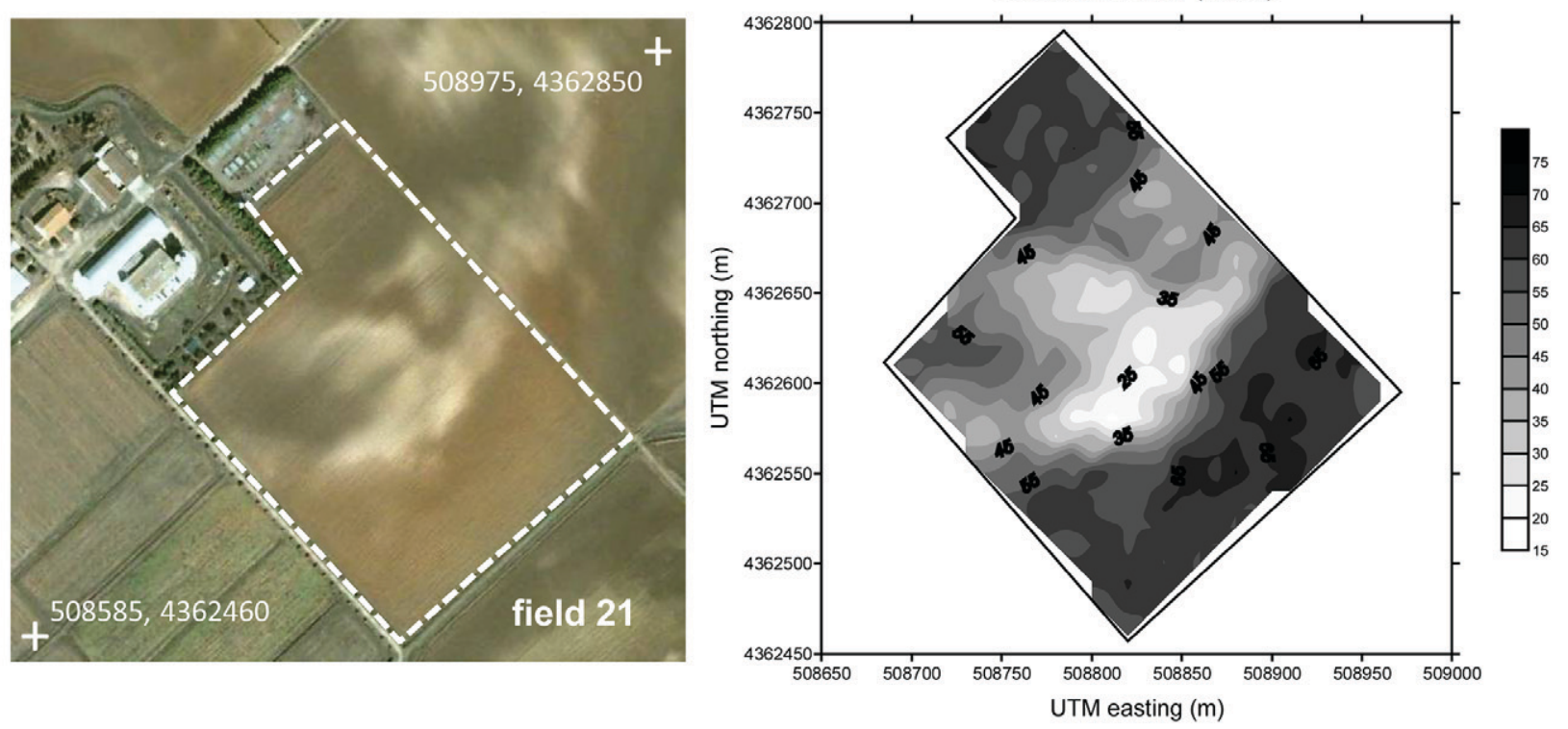

Fig. 3. Comparison between satellite image of Field 21 on 29 Oct. 2002 (bare soil image source: Google Earth) and the total $\gamma$-ray emission map obtained from soil mapping.
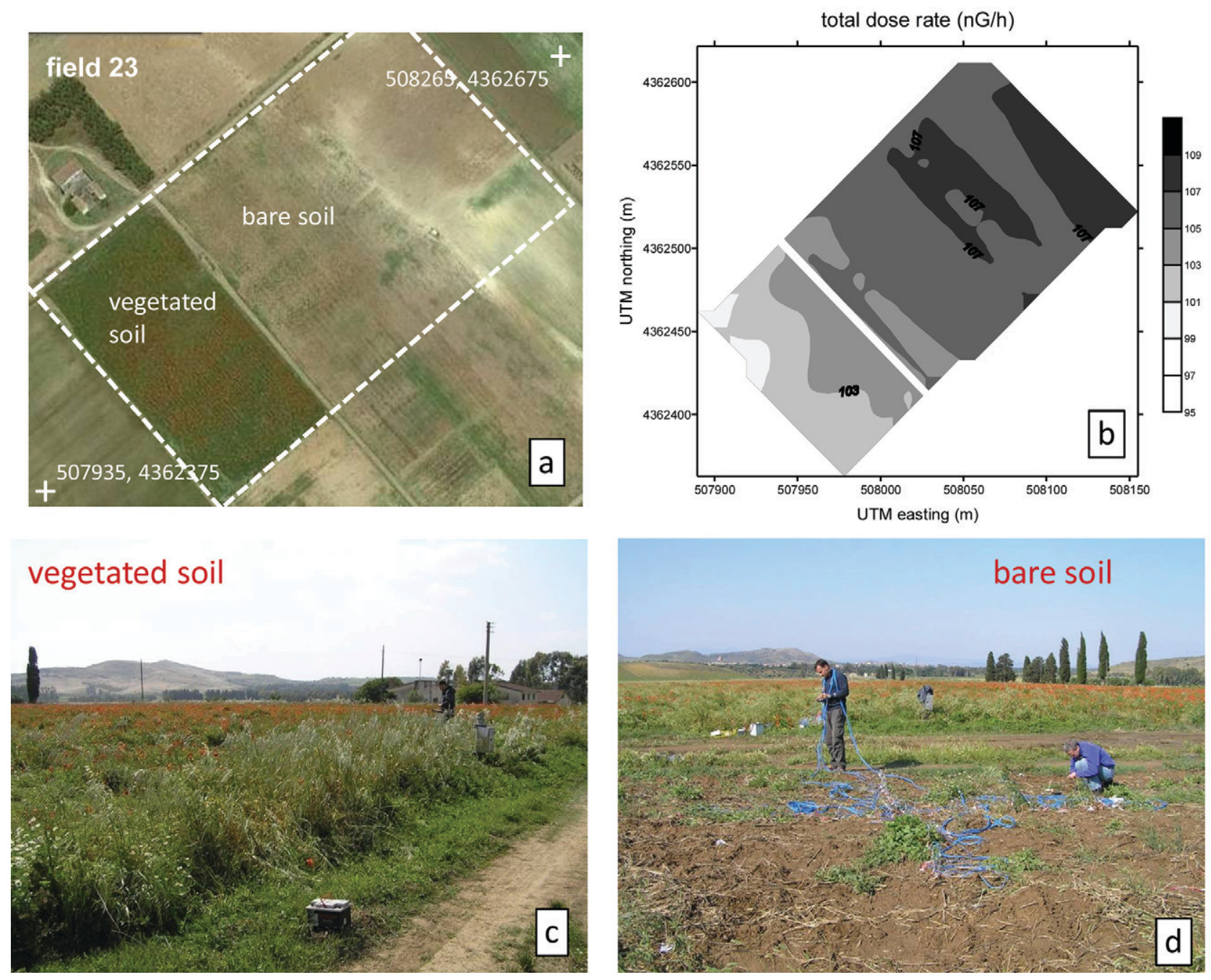

Fig. 4. Setup of the area where the irrigation experiment was conducted in May 2010: (a) satellite view of Field 23 (24 May 2010, image source: Google Earth) showing the vegetated and the bare plots; (b) total $\gamma$ ray emission map of the same area; (c) photo of the vegetated; and (d) of the bare soil plots. 
emission map collected in October 2010: note that the total dose rate variation is within a very narrow range (compare Fig. $4 \mathrm{~b}$ with the variations observed in Field 21 (Fig. 3b).

Before the irrigation experiment, we conducted an EMI survey in the area, covering both the vegetated and the bare plots, using a GF Instruments CMD1 sonde in low-penetration configuration, corresponding to an estimated total depth of investigation of $75 \mathrm{~cm}$. The results (Fig. 6) show a strong difference in average electrical conductivity of these top $75 \mathrm{~cm}$ in the two plots. The vegetated plot was considerably more resistive (on average a factor of 2) than the bare plot just a few meters away. This result is somewhat surprising as the bare soil has a crusty appearance, evidently as a result of evaporation from the top layer, while the soil in the vegetated plot was much wetter at the surface probably thanks to the shading provided by the vegetation against direct sunlight. On the other hand, given that the soil texture is the same in both plots, we could only attribute the difference in apparent electrical conductivity to the effect of vegetation, and its interaction with the local hydrology. During the period October 2009 to September 2010 the mean annual rainfall at the site was $500 \mathrm{~mm}$, while the temperature ranged between 10 and $30^{\circ} \mathrm{C}$. The estimated mean annual evapotranspiration was between 100 and $200 \mathrm{~mm}$ (Agenzia Regionale per la Protezione dell'Ambiente Sardegna, 2011).

To obtain detailed information about the system's changes as a result of a controlled irrigation, we deployed two electrical resistivity tomography (ERT) lines, one in each plot. Each line was composed of 24 electrodes spaced 20 $\mathrm{cm}$, for a total length of $4.6 \mathrm{~m}$ each, and an expected depth of investigation not exceeding $1 \mathrm{~m}$. These lines were left in place throughout the experiment until $4 \mathrm{~d}$ after irrigation. Time-lapse measurements were taken periodically, using a
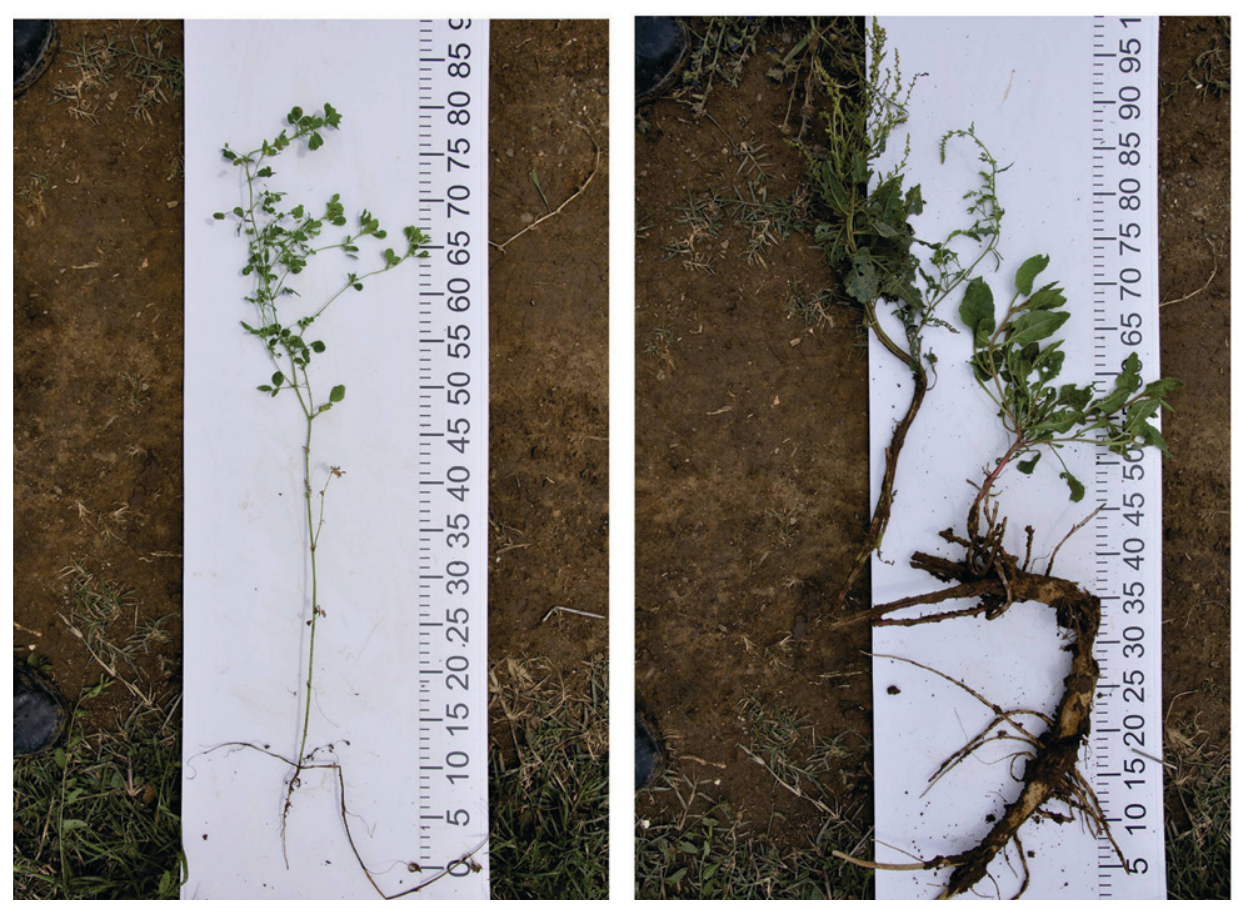

Fig. 5. Field 23: Typical root length (left) in the cultivated plot and (right) in the bare soil where spontaneous and sparse vegetation grows.

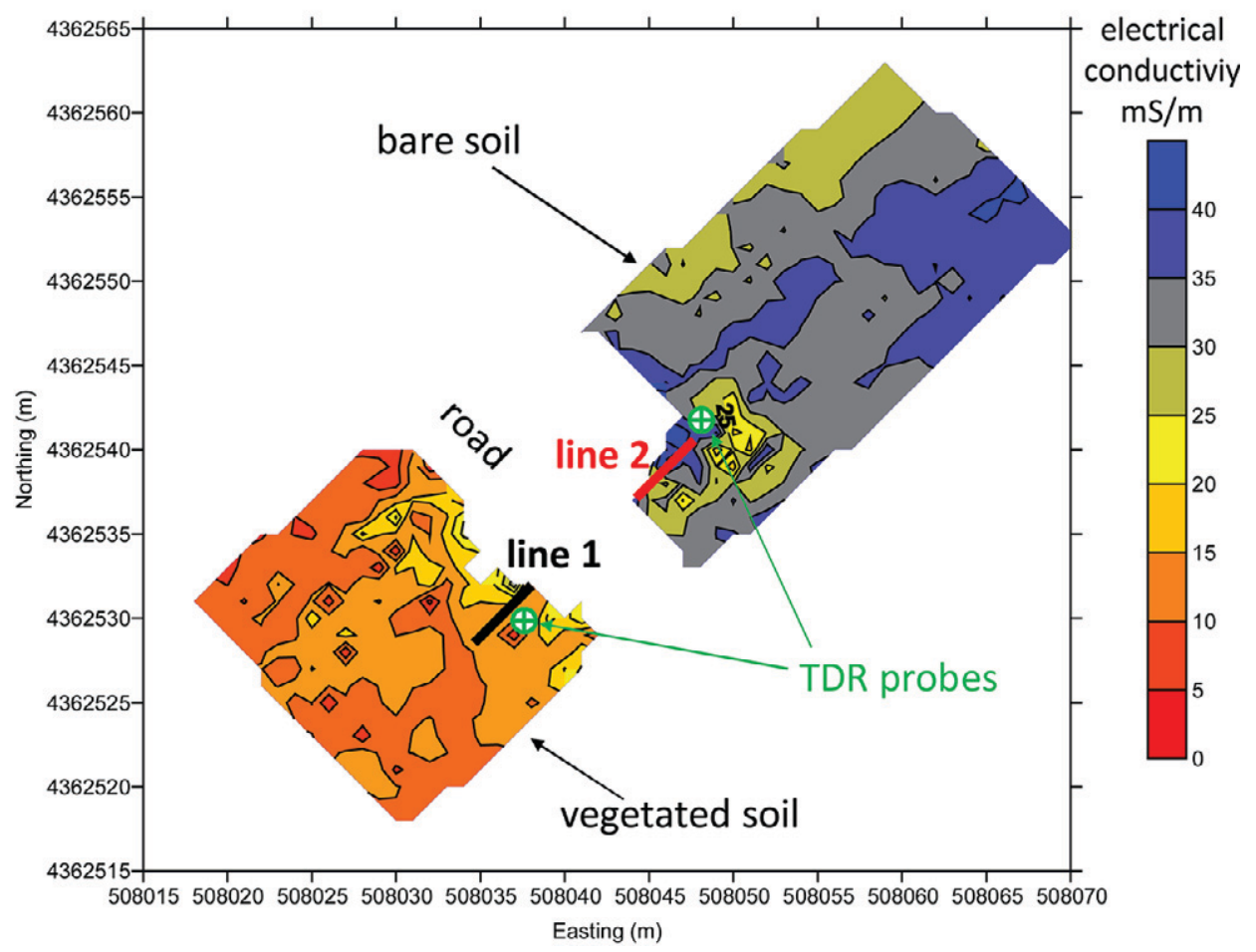

Fig. 6. The results of the small-scale electromagnetic induction survey conducted on 18 May 2010 on the part of Field 23 used for the irrigation experiment. The survey was conducted with a GF Instruments CMD1 sonde in horizontal loop configuration, with a nominal penetration depth of $0.75 \mathrm{~m}$. Both the vegetated and the bare soil plots were surveyed. The figure also shows the location of the two electrical resistivity tomography lines used for irrigation monitoring and of the fixed time domain reflectometry probes, in both plots. At the same time TRASE measurements were run at random georeferenced locations on both fields to measure the average moisture content in the top $0.10 \mathrm{~m}$. 
dipole-dipole skip 0 scheme (i.e., with dipole length equal to one electrode spacing) and full acquisition of reciprocals to estimate the data error level (see e.g., Monego et al., 2010). Consistently, the data inversion used an Occam inversion approach as implemented in the ProfileR/R2/R3 software package (Binley, 2011) accounting for the error level estimated from the data themselves. The skip 0 scheme allows for the highest achievable resolution and still produces significant signal/noise ratios given the short dipole distances used in these acquisitions.

The noninvasive monitoring has been complemented by (i) fixed TDR probes $(32 \mathrm{~cm}$ and $50 \mathrm{~cm}$ ) located next to the ERT lines (Fig. 6), periodically monitored with a Tektronix 1502 instrument; and (ii) a roaming 10-cm TRASE probe (Soilmoisture Equipment Corporation), that unfortunately failed after the background measurements on 19 May 2010. Figure

May 19 17:30

$13 \mathrm{~mm}$ rainfall during night

May 20 9:30

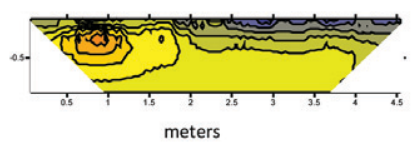

May 20 12:30

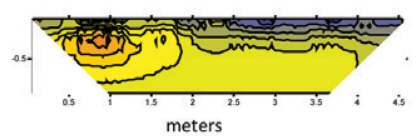

$42 \mathrm{~mm}$ irrigation during night

\section{May 21 10:30}

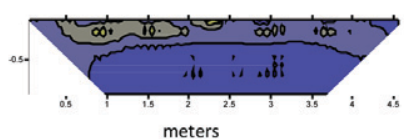

\section{May 24 15:30}

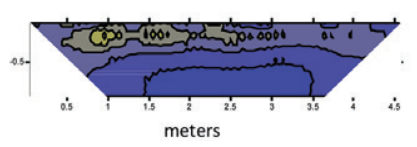

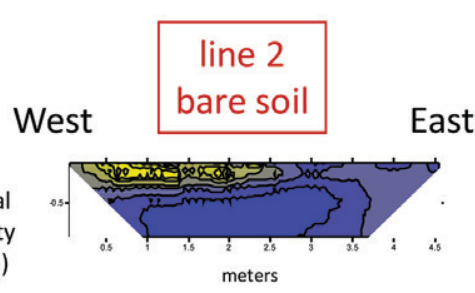

(Ohm m)
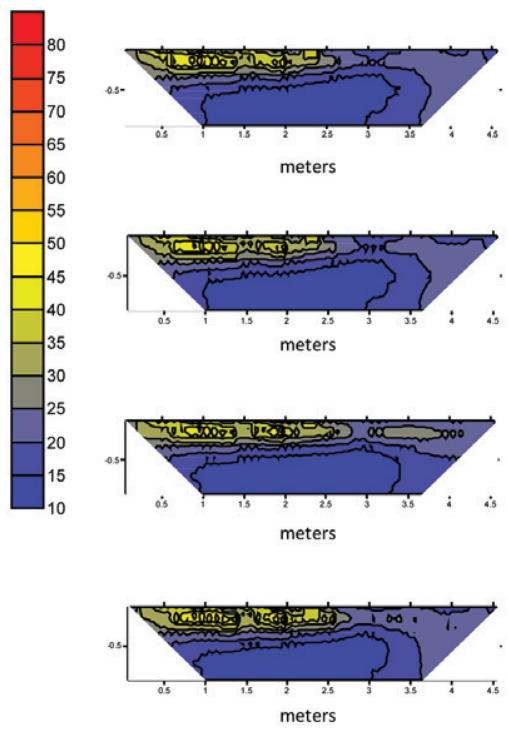

Fig. 7. Sequence of electrical resistivity tomography lines collected over lines 1 and 2 (see Fig. 6 for location) before and after the irrigation was applied to both vegetated and bare soil plots in Field 23.

7 shows the results of the ERT monitoring (lines 1 and 2) of the irrigation experiment. In particular, the background images (19 May 2010) show that indeed the ERT profile in the vegetated plot (line 1 ) is substantially more resistive than the equivalent profile (line 2) in the bare soil. In fact, the two profiles are nearly mirrored.

1. In the vegetated plot, a (relatively) resistive subsoil underlies a thin, more conductive soil layer at the top. Our tentative explanation is that (i) the top layer is moist, as it is shaded from direct sunlight by the canopy, while (ii) the deeper soil is relatively dry, as roots manage to extract soil moisture content from a depth in the 1-m range, mostly through suction, as the roots themselves are relatively shallow (Fig. 5).

2. In the bare plot, a more conductive soil layer underlies a thin, more resistive top layer. Here our tentative hypothesis is that the topsoil is strongly affected by evaporation due to direct sunlight and exposure to the warm air (no continuous canopy is present), thus protecting the underlying soil from evaporation (the top crust has reduced hydraulic conductivity).

The ERT background results are totally consistent, also quantitatively, with the EMI maps in Fig. 6 particularly if we consider that the EMI data refer to an average over the soil down to $75 \mathrm{~cm}$.

The night before the experiment (between 19 May and 20 May) a natural $13-\mathrm{mm}$ rainfall event occurred over the farm. The irrigation experiment took place overnight between 20 May and 21 May 2010: about $42 \mathrm{~mm}$ of irrigated water was applied to both vegetated and bare soils covering the entire area surrounding the two ERT lines.

The effects of both natural rainfall and irrigated water is shown, for both ERT lines, in Fig. 7. Three aspects are clearly noticeable.

1. The 13-mm natural rainfall seemed to cause little to no effect on the ERT images. This may be slightly surprising, but it can be explained by (i) the rainfall interception on the canopy for line 1 , and (ii) the large runoff fraction caused by the soil crust on line 2.

2. The 42-mm controlled irrigation causes a dramatic change in the images of ERT line 1: suddenly they become very similar to the background image along line 2. A possible explanation is that the large rate of infiltrating water replenished the water deficit caused by evapotranspiration in the vegetated plot.

3. The 42-mm controlled irrigation has no noticeable effect on ERT line 2: This can be again explained by the low hydraulic conductivity of the soil crust covering the bare plot, drawing most irrigated water into runoff onto the road and/or locally ponded water that is rapidly evaporated in absence of a protecting canopy.

These phenomena seem to point toward the existence of well defined mechanisms associated to the presence of vegetation. The presence of roots, albeit short and thin, is clearly capable of enhancing the infiltration capacity of the vegetated plot: this is a positive feed-back mechanism that enhances the replenishment of the water reservoir available to vegetation. Indeed, the background 
ERT and EMI images demonstrate that vegetation can effectively draw water from a depth exceeding half a meter; that is the depth replenished as a consequence of the intense artificial irrigation input. On the other hand, the absence of an extensive vegetal cover on the western plot causes the formation of a low permeability dry topsoil layer that protects the underlying soil from evaporation and maintains a high moisture content in the underlying soil layer. On the other hand, the impermeable dry topsoil also limits infiltration into the subsoil.

The above discussion is necessarily limited to qualitative terms. We made an attempt to quantify the meaning of the ERT monitoring by calibrating a suitable constitutive relationship linking electrical conductivity and moisture content. Given the relatively large fine grain fraction (see Table 1) it is necessary to account for grain surface conductivity in the constitutive relationship (consider, e.g., Brovelli and Cassiani, 2011). A classical approach, albeit somewhat limited, is to use the Waxman and Smits (1968) model in its unsaturated porous media form:

$$
\sigma=\frac{S^{n}}{F}\left(\sigma_{W}+\frac{\sigma_{S}}{S}\right)
$$

where $\sigma$ is the bulk electrical conductivity $(\sigma=1 / \rho$, where $\rho$ is the electrical resistivity derived e.g., from the ERT inversion); $\sigma_{\mathrm{W}}$ is the pore water electrical conductivity; $\sigma_{S}$ is the equivalent grain surface conductivity; $S$ is water saturation $(0 \leq S \leq 1)$; $n$ is referred to as the saturation exponent; $F$ is Archie's formation factor, that can be expressed as $F=1 / \phi^{m}$, where $\phi$ is porosity, and $m$ is the so-called Archie's cementation exponent. To reduce the number of independent parameters we assumed $m=n$. This assumption is justified as we did not seek to characterize the spatial variability of porosity, and in absence of these data an independent calibration of $m$ is impossible. In addition, as we are interested only in the variation of electrical conductivity with saturation, any other parameterization that describes the formation factor would be effectively equivalent.

We used Eq. [1] to model the transformation from electrical conductivity to water saturation. To fix the model parameters we first decided to try and honor the in situ moisture content measurements provided by TDR and TRASE probes in the vegetated plot, where moisture content changes are extreme. This was done by (i) taking the horizontal averages of the line 1 ERT resistivity images in Fig. 7, thus constructing one-dimensional resistivity profiles as a function of depth only; (ii) Monte Carlo simulations exploring the parameter space and identifying the optimal parameter set that transforming the one-dimensional resistivity profiles above, satisfies, in a least squared sense, the TDR data on 19 May and on 24 May 2010, that is, at the beginning and end of the irrigation experiment, and the TRASE data on 19 May.

The result of this fitting procedure is shown in Fig. 8. Note that it has not been able to reproduce the TRASE average value on
19 May. This is hardly surprising, as the TRASE data are limited to the $10 \mathrm{~cm}$ depth of the TRASE probe, while the resolution of the ERT-derived moisture content estimations cannot be any finer than the $20 \mathrm{~cm}$ electrode spacing (actually, lower than that). The TDR data are reasonably well fitted by Eq. [1] with the optimal parameters: $\phi=0.391 ; n=m=2.42 ; \sigma_{\mathrm{W}}=6.48 \times 10^{-2} \mathrm{~S} / \mathrm{m} ; \sigma_{\mathrm{S}}$ $=0.982 \mathrm{~S} / \mathrm{m}$.

Several soil samples from the top $30 \mathrm{~cm}$ were used for laboratory measurements of electrical resistivity as a function of water saturation. Tap water was used to saturate the samples during these experiments, with an average water conductivity equal to $4.9 \times$ $10^{-2} \mathrm{~S} / \mathrm{m}$. The water extracted during desaturation, after contact with the sample soil, had an electrical conductivity equal to $6.6 \times 10^{-2} \mathrm{~S} / \mathrm{m}$, i.e., very close to the $\sigma_{\mathrm{W}}$ value obtained by fitting the ERT data to the field TDR measurements using Eq. [1]. Desaturation and resistivity measurement were performed similar to the procedure described in Cassiani et al. (2009). The laboratory measurements were conducted at $20^{\circ} \mathrm{C}$, i.e., very similar to the in situ temperature in late May 2010 at the San Michele site $\left(18^{\circ} \mathrm{C}\right)$. Figure 9 shows the comparison between the Waxman and Smits (1968) relationship (Eq. [1]), fitted to the field data, and the laboratory data. While a nonnegligible scatter is clearly present in the laboratory results, the calibrated Eq. [1] is largely compatible with the laboratory results.

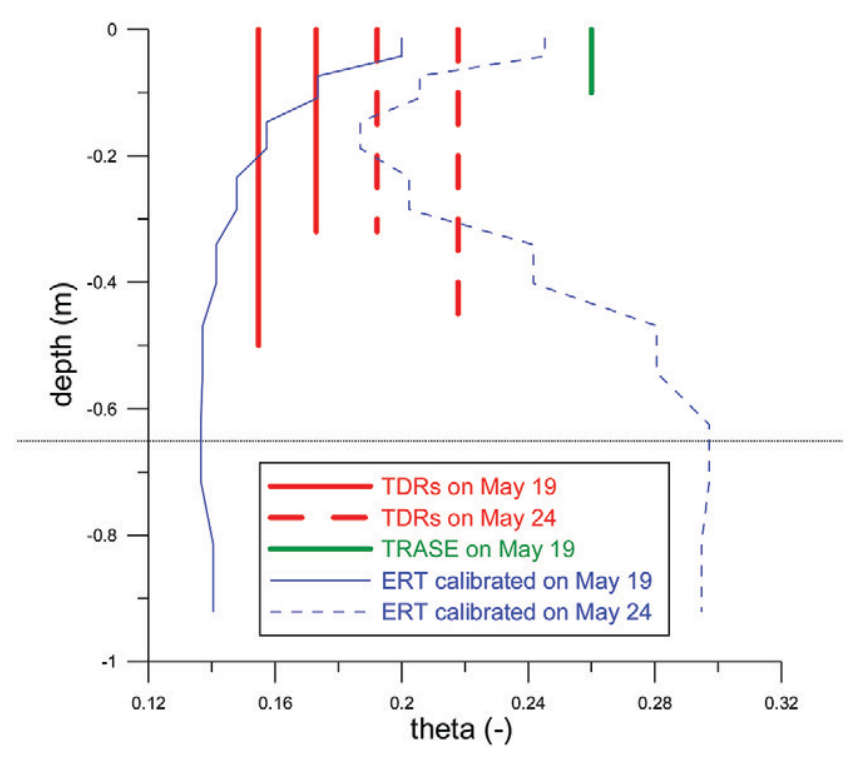

Fig. 8. Calibration of electrical resistivity tomography inversion results against in situ time domain reflectometry and TRASE measurements of moisture content over the vegetated plot. The curves of moisture content as a function of depth are obtained taking the horizontal averages of the line 1 electrical resistivity tomography resistivity images of 19 May and 24 May 2010 in Fig. 7, that is, at the beginning and end of the irrigation experiment, and transforming resistivity into moisture content values with Eq. [1] calibrated on time domain reflectometry and TRASE data. The horizontal dotted line marks the maximum depth considered reliable for the electrical resistivity tomography-derived profiles, that is, the one that correspond to a correct mass balance of infiltrated water. 
Figure 8, however, demonstrates the existence of one remaining pending issue: the integral of moisture content change between 19 May and 24 May 2010, taken from the ground surface to the maximum depth of about $92 \mathrm{~cm}$ (about $100 \mathrm{~mm}$ ) exceeds the total known infiltrated water $(55 \mathrm{~mm}$ ). In fact a large percentage (nearly $50 \%$ ) of the moisture content change integral lies in the bottom $30 \mathrm{~cm}$ of the profile, i.e., the region where surface ERT resolution is poorest. Mass balance issues from ERT inversion of tracer test monitoring data is known to exist and can lead to severe balance errors (e.g., Singha and Gorelick, 2005): This phenomenon is well established to be a consequence of resolution limitations of geophysical data (Cassiani et al., 1998; Day-Lewis et al., 2005). Since the poorest resolution in ERT images is necessarily present at depth, it is reasonable to trust the ERT results down to a depth compatible to the need to honor mass balance, i.e., to roughly 60 $\mathrm{cm}$ depth (see Fig. 8). All water mass that appears to be deeper than this depth is probably only caused by an extrapolation of the electrically more conductive layer put in place by the irrigation between 30 and $60 \mathrm{~cm}$ depth. To give some confirmation of this hypothesis, we ran a synthetic exercise relevant to the ERT acquisition on the vegetated field on 24 May. First we considered a one-dimensional resistivity versus depth profile obtained from horizontally averaging the two-dimensional ERT inverted section (the one at the bottom of Fig. 7). This profile is the one used to derive the moisture content profile in Fig. 8. We extended this profile to larger depth, as needed for synthetic modeling and we generated a forward dataset with the same configuration as the field acquisition. This dataset was then inverted with the same data error (5\%): the result is shown in Fig. 10 as synthetic (a). We then modified the profile at depths larger than $62 \mathrm{~cm}$ adopting a larger resistivity value, roughly equal to the maximum observed close to the surface, and the corresponding inverted image is also shown in

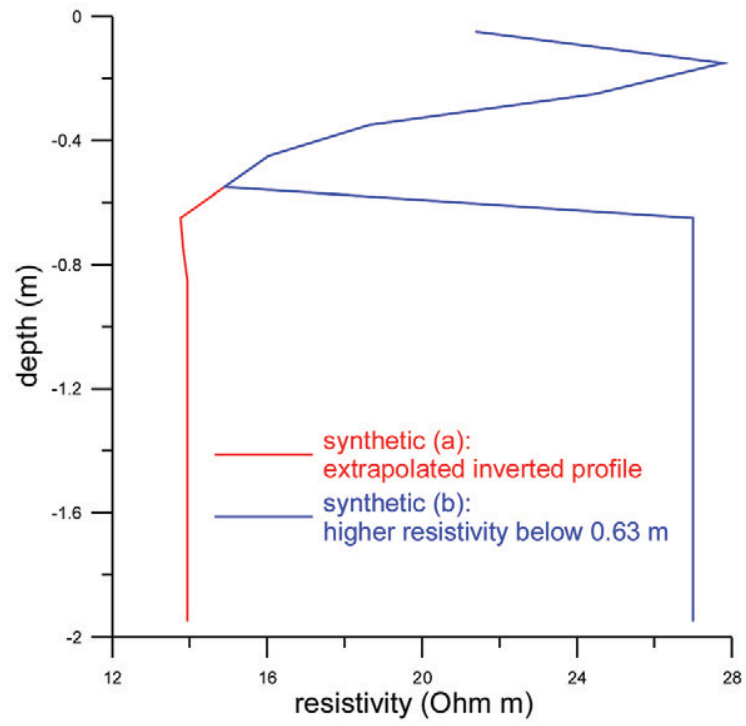

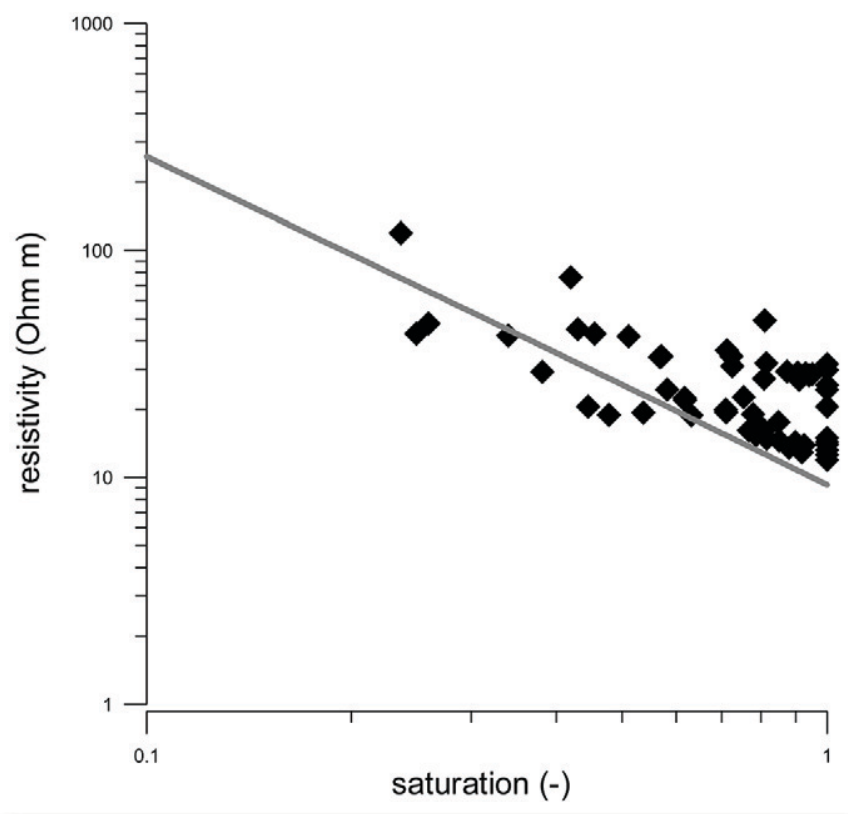

Fig. 9. Laboratory data on soil samples from the San Michele farm (diamonds) compared against the field-calibrated Waxman and Smits relationship (Eq. [1]).

Fig. 10 as synthetic (b). Both synthetic results are compared with the real inverted data: even though the test is not conclusive, the images in Fig. 10 seem to indicate that the true data are likely to correspond to a situation intermediate between the two synthetic (one-dimensional) cases, confirming the low resolution characteristics of the inversion at depths larger than about $60 \mathrm{~cm}$.

Given the above, we accepted the Waxman and Smits relationship with the parameters fitted to the field TDR data, and corroborated

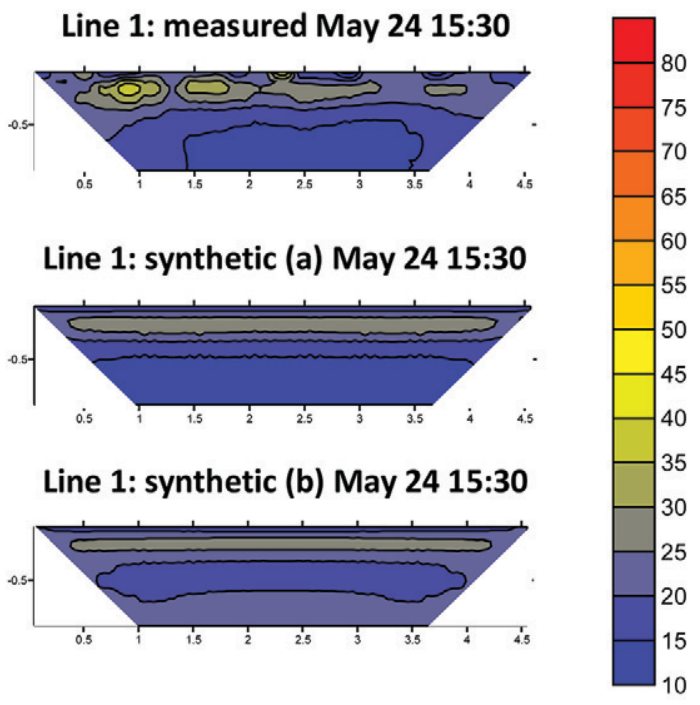

Fig. 10. Sensitivity analysis with respect to the actual resistivity profile below $0.63 \mathrm{~m}$, that is, the depth down to which the electrical resistivity tomography inversion is considered reliable. On the left the two profiles used in the synthetic forward/inverse modeling: (a) is the inverted profile on 24 May (see Fig. 8) extrapolated to larger depth; (b) is the same profile down to $0.63 \mathrm{~m}$, but with higher resistivity deeper than that. On the right the corresponding synthetic electrical resistivity tomography inversion results compared against the actual inverted electrical resistivity tomography image. 
by the laboratory measurements, as our best estimate of the relationship between electrical resistivity and moisture content, and thus converted all ERT sections collected during the irrigation experiment (Fig. 7) into moisture content sections (Fig. 11). The most prominent features of this result are (i) the large difference in moisture content observed between vegetated and bare fields, and (ii) the dramatic effect that irrigation has on the vegetated plot, apparently restoring the subsoil moisture content conditions to a situation similar to the one observed in the bare plot. We argue that the pre-irrigation difference is mainly caused by the evapotranspirative effect of the vegetation, and that irrigation only replenishes the depleted soil reservoir in the soil top $60 \mathrm{~cm}$.

\section{Seasonal Monitoring: Results and Discussion}

We also performed the time-lapse hydrogeophysical monitoring of the soil hydrological dynamics under natural conditions. The technique we utilized (EMI) is most sensitive to changes in the hydrological state of the system, particularly to its moisture content. However temperature changes cannot be neglected. The changes considered are naturally induced by the different forcing conditions (e.g., precipitation, evapotranspiration) that strongly depend on the season. The ultimate aim is to translate the time and space dependent geophysical data into quantitative estimates of the hydrological state variables, distributed in space and time, that in turn shall be part of the dataset for hydrological model calibration.

Monitoring started in May 2009 and is currently ongoing (December 2011). The dataset is composed of a good number of repeated frequency-domain electromagnetic measurements particularly focused on Field 21. The acquisition has been performed using a GF Instruments CMD1 electro-magnetometer in low penetration configuration (horizontal loops) with a nominal penetration of about $0.75 \mathrm{~m}$. Most of the measurements have been performed manually and are automatically georeferenced using a Trimble GPS with decimetric precision in horizontal positioning. Note that, given the high soil electrical conductivity, GPR does not produce usable results, as the signal is quickly attenuated in the subsurface. Therefore neither structural information nor timelapse measurements of soil moisture content are possible using this technique.

Temperature effects have been accounted for by correcting the EMI electrical conductivity readings ( $\mathrm{EC}_{\mathrm{a}}$ ) according to the relationship proposed by Sheets and Hendrickx's (1995) and discussed in detail by Ma et al. (2011):

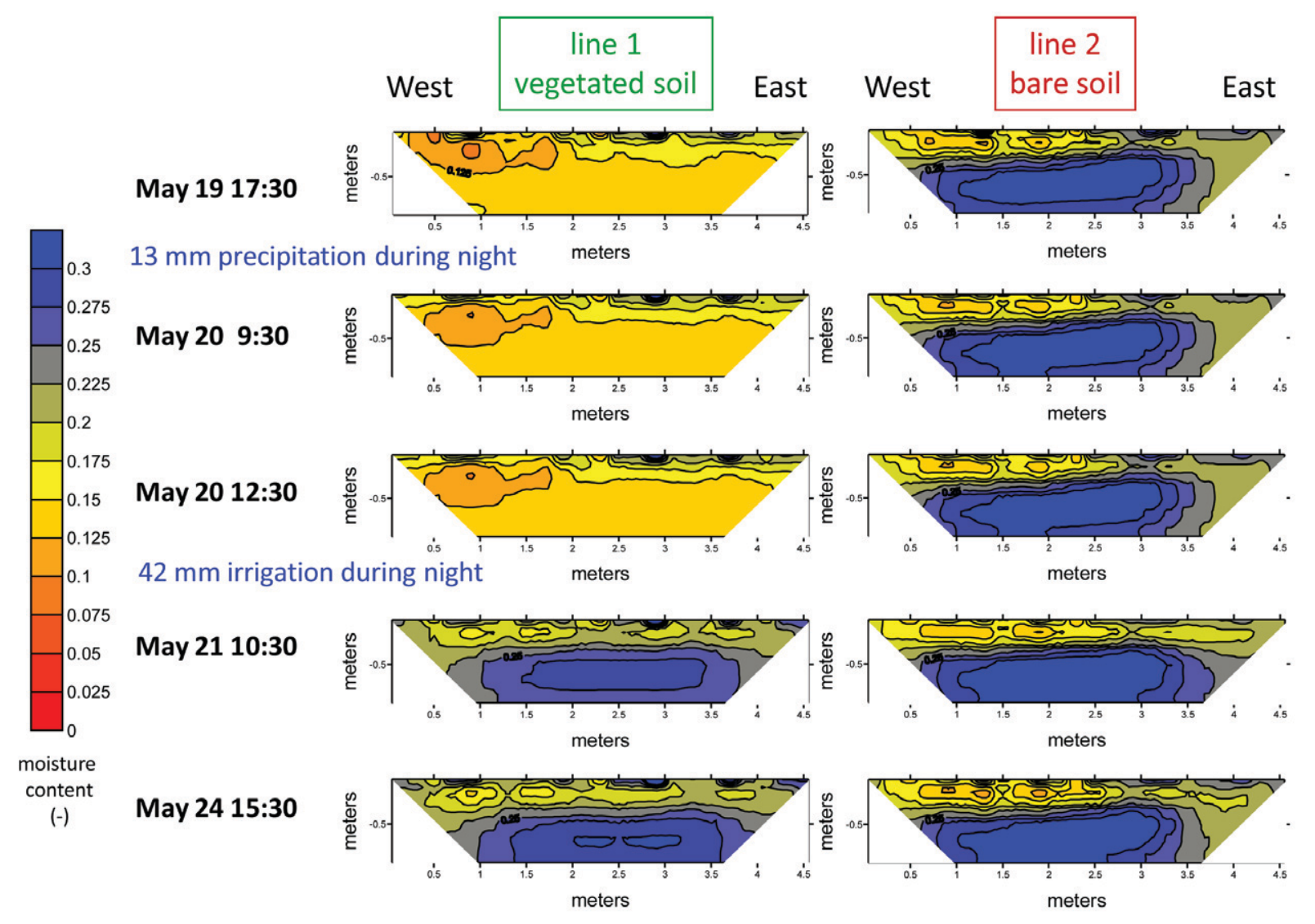

Fig. 11. Sequence of electrical resistivity tomography lines collected over lines 1 and 2 before and after the irrigation, converted into estimates of moisture content according to the calibrated Eq. [1] (see Fig. 9). 
$E C_{25}=E C_{a}\left[0.4470+1.4034 e^{-(T / 26.815)}\right]$

where $E C_{25}$ is the $E C_{a}$ standardized at $25^{\circ} \mathrm{C}$ and $T$ is the soil temperature $\left({ }^{\circ} \mathrm{C}\right)$. Estimates of soil temperature have been derived from average monthly air temperatures recorded on site. Similarly the bulk conductivity in the calibrated Eq. [1] can be normalized to $25^{\circ} \mathrm{C}$ to transform $\mathrm{EC}_{\mathrm{a}}$ readings into estimated average moisture content in the top $0.75 \mathrm{~m}$ of soil. Figure 12 shows a sequence of such estimated moisture content maps on Field 21 from September 2010 to October 2011. During this period the field was maintained free of vegetation by herbicide application. This practice was interrupted between the beginning of February and the end of March 2011, and consequently a mixture of spontaneous species grew with a prevalence of oilseed rape.

The moisture content maps in Fig. 12 show three main features.

1. In all seasons the spatial patterns of moisture content are well defined and repeatable, showing an area of higher moisture content to the western side of the site. The higher moisture content is effectively correlated with the fine soil fraction (clay+silt: see Fig. 2) while it is not so obviously correlated with $\gamma$-ray emission that is strongly controlled by the abundance of $\mathrm{CaCO} 3$ (Fig. 3 ) thus probably masking the more subtle fine fraction effect.

2. Moisture content changes substantially over time, and as expected is much lower over summer (below 8\%) than in winter-spring (as high as 22\%).

3. In March 2011 the most dense spontaneous vegetation is concentrated in the area where higher moisture content is always observed, i.e., in the region of finer soil texture. Here the canopy reached more than $2 \mathrm{~m}$ in height, making it difficult even to walk through this area. Elsewhere in Field 21 the vegetation appeared to be sparse and large patches of bare soil still remained, similar to the situation of the bare soil plot in Field 23. Note that the dense vegetation is here correlated with higher rather than lower moisture content in the soil as observed in Field 23 in May 2010. However this is not surprising, as (i) we are here considering data related to an earlier period (March versus May) with a different evapotranspiration demand, and (ii) the finer soil texture in the western area of Field 21 is a factor controlling the vegetation growth.

Figure 13 shows another interesting phenomenon linked to the interaction between vegetation and soil state. Here the estimated moisture content maps in May 2009, May 2010, and May 2011 are compared. The EMI surveys were conducted roughly at the same date. For May 2010 this corresponds to the time of the irrigation experiment in Field 23.

In January-February 2010 the south-eastern portion of the field was seeded with wheat, and in May 2010 this was fully grown. On the contrary, in both May 2009 and May 2011, the whole field was bare. The wheat area is marked by the thick line in Fig. 13. The presence of wheat has a distinct effect on moisture content patterns, reducing moisture content basically to the level observed in the vegetated plot of Field 23 at the same time (10-12\%) and erasing any pattern observable in 2009 and 2011 over the same area, and likely linked to soil texture subtle patterns. The remaining part of Field 21, always left bare, shows the same features in May 2009, 2010, and 2011. Note that Field 21 was, up to May 2011, not irrigated.

\section{Model}

The phenomena observed in the field irrigation experiment and longterm monitoring, particularly the interactions between soil moisture content and vegetation, call for the development of a mechanistic model capable at least of capturing the main controlling features. In this section, we would like to provide a tentative theoretical framework that could support our hypothesis that the significant differences that characterize the biomass and water dynamics in bare and vegetated plots of Field 23 could be ascribed to the water stress that originates from the scarce wettability of the bare soil, that is just partially contrasted by the vegetation growth. Furthermore, we would discuss what could cause the very different soil moisture patterns observed in the two noncultivated plots of Field 21 and 23 where the vegetation density and the soil saturation are respectively very high and quite low, finally we would discuss how the soil- vegetation feedbacks could impact the water budget and the connectivity of the soil surface with the soil layers below the root zone.

We do not try to invert measurements but rather we try to translate soil moisture patterns into evidence of relevant processes in act and justify the link and relevance of these processes to the growth of different species, on the base of mass balance consideration. The following experimental evidences may be easily incorporated within simple biomass and water balance evaluation.

1. High biomass density corresponds to high soil moisture availability (at Field 21) and conversely a patchy distribution of vegetation (corresponding to low average biomass density) is associated to the persistent soil moisture deficit (at Field 23).

2. A feedback seems to exist between infiltration and vegetation growth according to the soil moisture patterns observed at Field 23 , if the scarce vegetation cover of the bare plot is associated with increased runoff and reduced infiltration.

3. A linkage seems to exist between the dynamics of soil moisture and the depth of the soil layer that participates to the dynamics of soil moisture (it could be expected to be related with the root depth). The linkage is evidenced by the comparison between the soil moisture patterns observed at the cultivated site (no water stress) and those observed at the bare plot of Field 23.

The conceptual model proposed in the following consists of two mass balance equations: one for the soil moisture and one for biomass (see Fig. 14 for a conceptual scheme of the model fluxes).

The rate of variation of the biomass density $B$ is the difference between the growth rate of the biomass $G$ and the mortality rate $M$ due to water scarcity.

$\frac{\mathrm{d} B}{\mathrm{~d} t}=G-M$ 

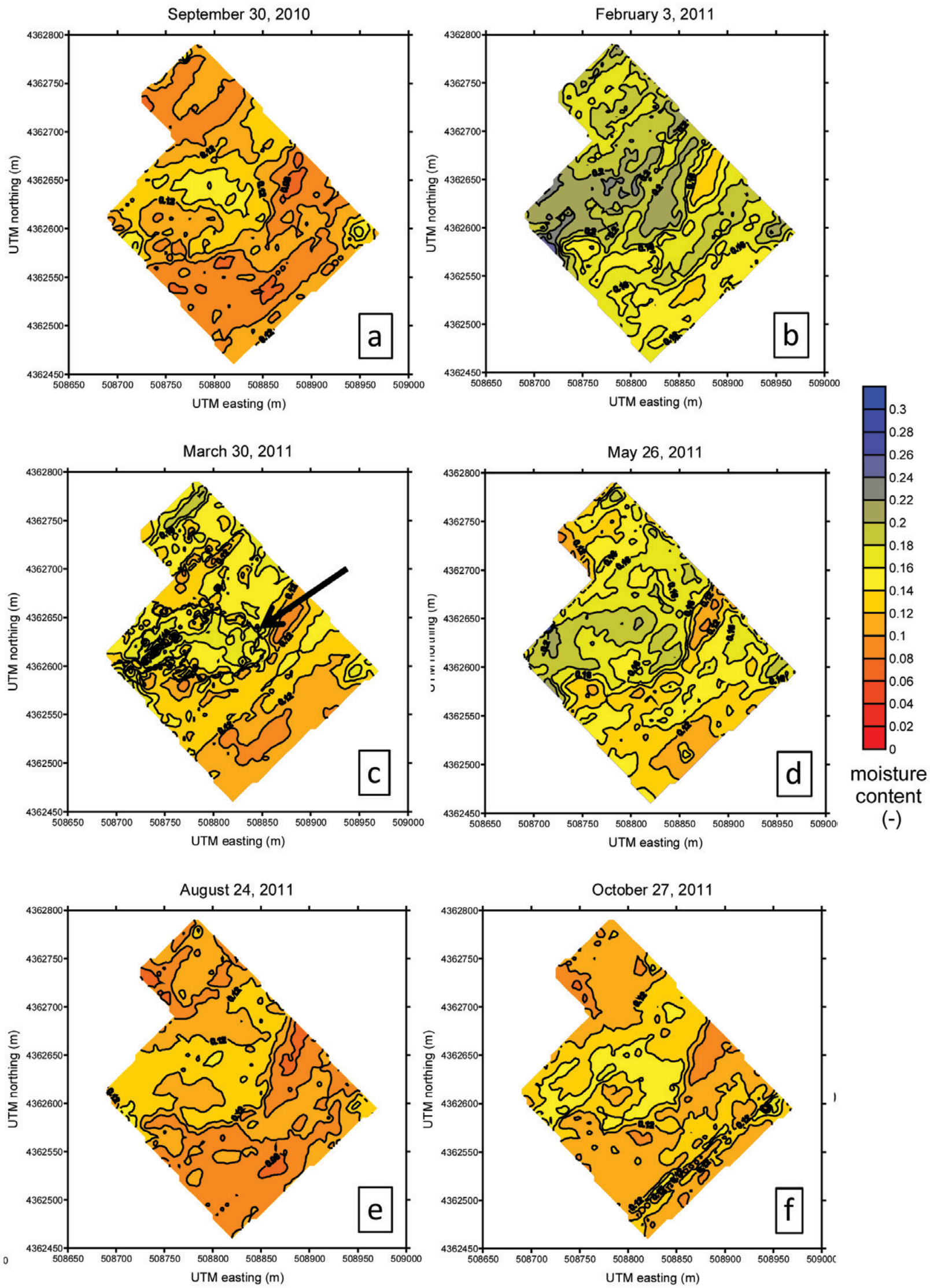

Fig. 12. Maps of estimated moisture content derived from EMI mapping on Field 21 during 2011. The ECa values have been temperature corrected and converted into moisture content using to the calibrated Eq. [1], see Fig. 9. The arrow in Fig. 12c points at the area covered by dense and tall spontaneous vegetation on 30 Mar. 2011. 

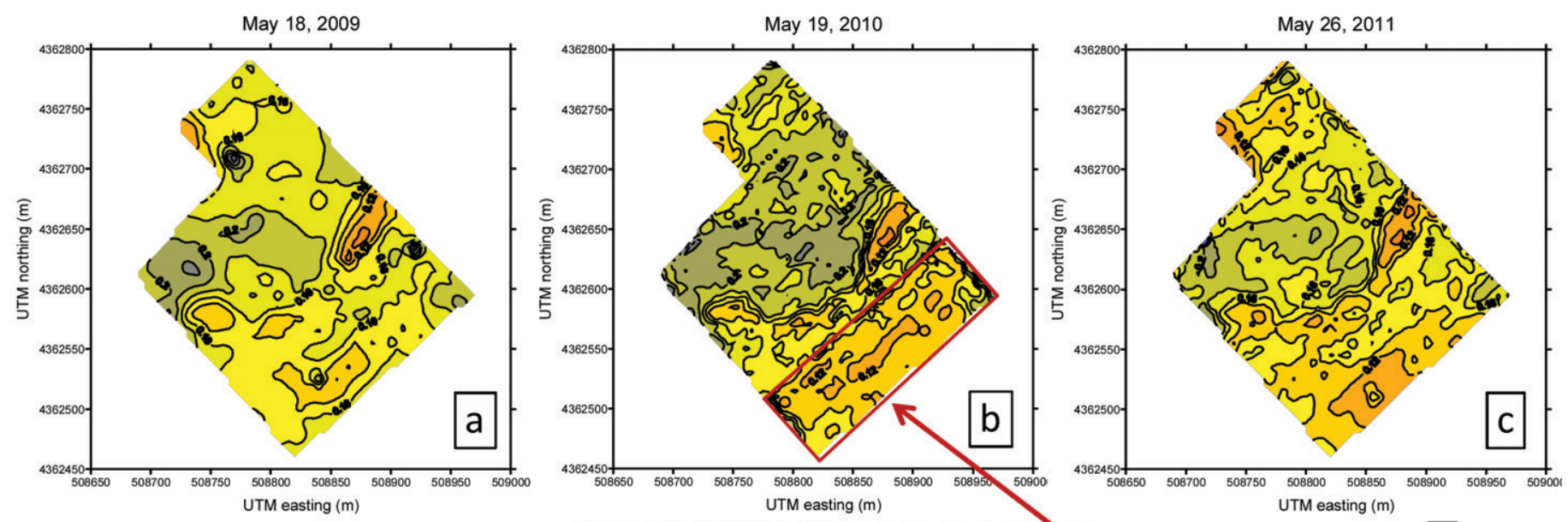

Fig. 13. Maps of estimated moisture content derived from EMI mapping on Field 21 in May 2009, 2010, and 2011. The ECa values have been temperature corrected and converted into moisture content using to the calibrated Eq. [1]. Note the clear effect of wheat grown in 2010 in the southern part of the field. Satellite image source: Google Earth.
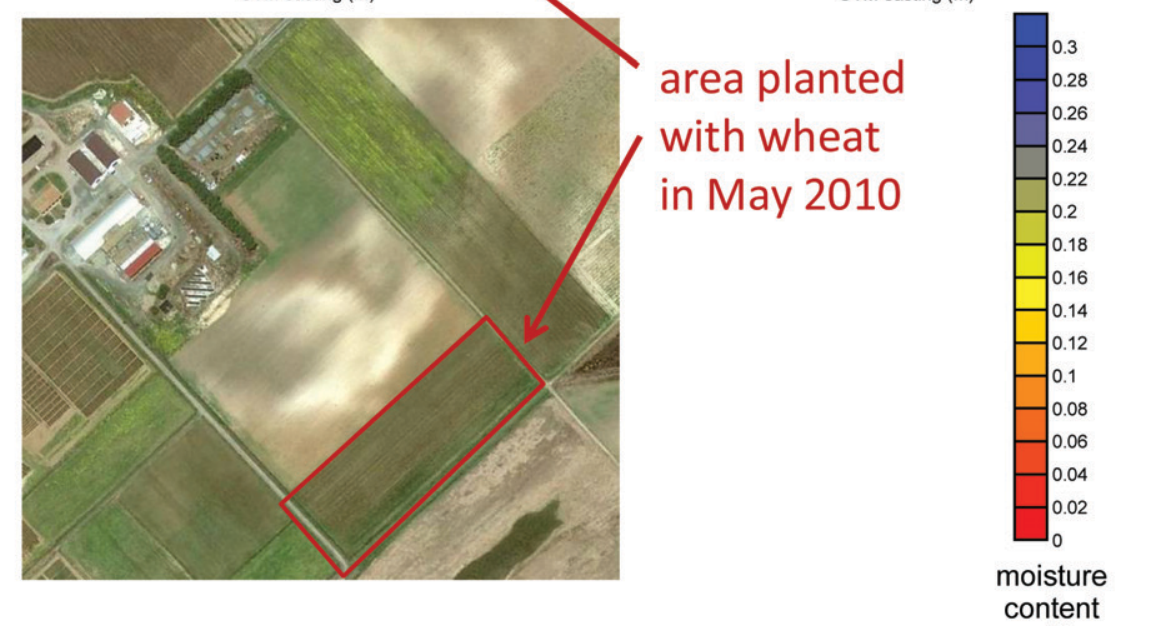

$(-)$

The time derivative of the soil moisture volume $n H S$, where $S$ is the soil saturation, $n$ the soil porosity and $H$ the root depth, equals the infiltration rate $I$ minus evapotranspiration ET and leakage $L$.

$n H \frac{\mathrm{d} S}{\mathrm{~d} t}=I-\mathrm{ET}-L$

According with our intuitive interpretation of the experimental data, we assume that infiltration is impeded in the absence of vegetation and furthermore, that infiltration and evapotranspiration both increase with increasing biomass density. The soil vegetation interaction affects leakage as well. We simulate the possible occurrence of fast flow from the soil surface to the water table by increasing the soil conductivity and thus $L$, under the hypothesis that roots create fast flow path to the detriment of soil moisture storage.

Parameters and functions are taken from literature and our speculation on the relevance of the soil vegetation feedbacks will serve to outline specifically dedicated further experiments. Functions $(G, M, I$, ET, $L)$, function parameters and related references are reported in Table 2. Equation [3] and [4] have been integrated on daily time scale for several years to lose memory of an arbitrary

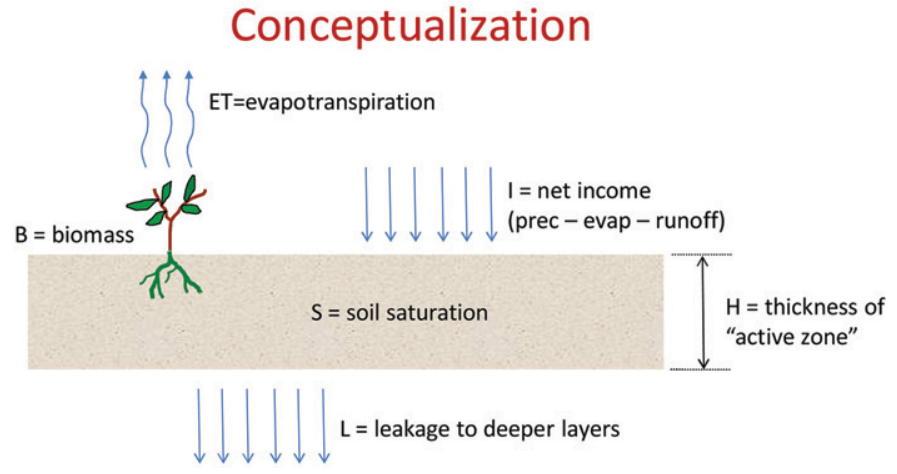

Fig. 14. Conceptual scheme of the model used in this paper.

initial condition and average estimate of the dimensionless biomass density $b=B / K_{\mathrm{b}}$ and of soil saturation $S$ are presented in Fig. 15 as a function of $H$, for different hypothetical environmental scenarios (see Table 2 for parameter definition).

When the partitioning of rainfall into infiltration and runoff is linked to the vegetation growth by a positive feedback between infiltration and biomass growth (as conjectured for the Field 21) the gain in storage capacity achieved by the plant that develops 
Table 2. Model function functionality, parameter definition, parameter values and related references.

\begin{tabular}{|c|c|c|c|}
\hline Model functions & Parameters & Parameter values & References \\
\hline$G(B)=r B\left(1-\frac{B}{K_{\mathrm{b}}}\right)$ & $\begin{array}{l}r=\text { specific growth rate and } \\
K_{\mathrm{b}}=\text { carrying capacity }\end{array}$ & $\begin{array}{l}r=1 \mathrm{yr}^{-1} \\
K_{\mathrm{b}}=5 \mathrm{~kg} \mathrm{~m}^{-2}\end{array}$ & $\begin{array}{l}\text { Verhulst (1838) } \\
\text { Lieth and Whittaker (1975) }\end{array}$ \\
\hline$M=m B \frac{1-S}{1+S}$ & $m=$ mortality rate & $m=1 \mathrm{yr}^{-1}$ & \\
\hline \multicolumn{4}{|l|}{$P=P_{0}(1+\sin 2 \pi t)$} \\
\hline$g=\frac{\frac{B}{K_{\mathrm{b}}}}{\frac{B}{K_{\mathrm{b}}}+k_{1}}$ & $k_{1}=$ feedback parameter & $k_{1}=0.25$ & $\begin{array}{l}\text { HilleRisLambers et al. (2001) } \\
\text { Ursino (2007) }\end{array}$ \\
\hline$L=K_{\mathrm{s}} S^{n}$ & $\begin{array}{l}K_{\mathrm{s}}=\text { soil saturated conductivity } \\
n=\text { soil empirical parameter }\end{array}$ & $\begin{array}{l}\mathrm{K}_{\mathrm{s}}=300 \mathrm{~mm} \mathrm{yr}^{-1} \\
n=0.5(\mathrm{a} ; \mathrm{c}) \\
n=5(\mathrm{~b} ; \mathrm{d})\end{array}$ & $\begin{array}{l}\text { Brooks and Corey (1964) } \\
\text { Kim et al. (1996) } \\
\text { Ursino (2009) }\end{array}$ \\
\hline
\end{tabular}

deep roots, does not represent an advantage for the plant itself as roots grow deeper. Above a certain threshold $H, b$, and $S$ become less sensitive to further increase in root depth.

The "critical" root depth at which plant cover no longer affects the soil moisture balance and thus the water yield depends on plant physiology and phenology (through ET) and on the soil vegetation interaction and feedback that alter the soil wettability and conductivity (and thus $I$, and $L$ ). Modeled and observed (at the bare plot of Field 23) "critical" root depth are in the same order of magnitude of about $500 \mathrm{~mm}$.

The occurrence of a water stress situation is associated to the occurrence of a patchy vegetation cover (low $S$ corresponds to low $b$ ). According to a simple mass balance approach, water stress may be attributed to the physiological high water demand ( when $\mathrm{ET}_{0}=500 \mathrm{~mm} \mathrm{yr}^{-1}$ cases: $\mathrm{c}$ and $d$ (from Fig. 15 and Table 2), the effective evapotranspiration corresponds to the literature data taken here as reference values due to the low biomass density, but it is locally very high) or to a disadvantageous partitioning of rainfall into runoff due to the lack of soil wettability where the vegetation does not grow $\left(\left.I(b)\right|_{b=0 / 1}=0 / 0.8 I_{0}\right.$ ) or to enhanced leakage when the root growth coincide to the establishment of a fast connection of the soil surface with the water table (simulated by setting $n=0.5$ in cases a and c). The model outcome demonstrates that (i) vegetation may affect the soil structure and enhance leakage and/or infiltration producing a negative or positive feedbacks, (ii) preferential allocation of biomass below ground determines and increment of soil storage capacity but does not always turn into an advantage for biomass growth.

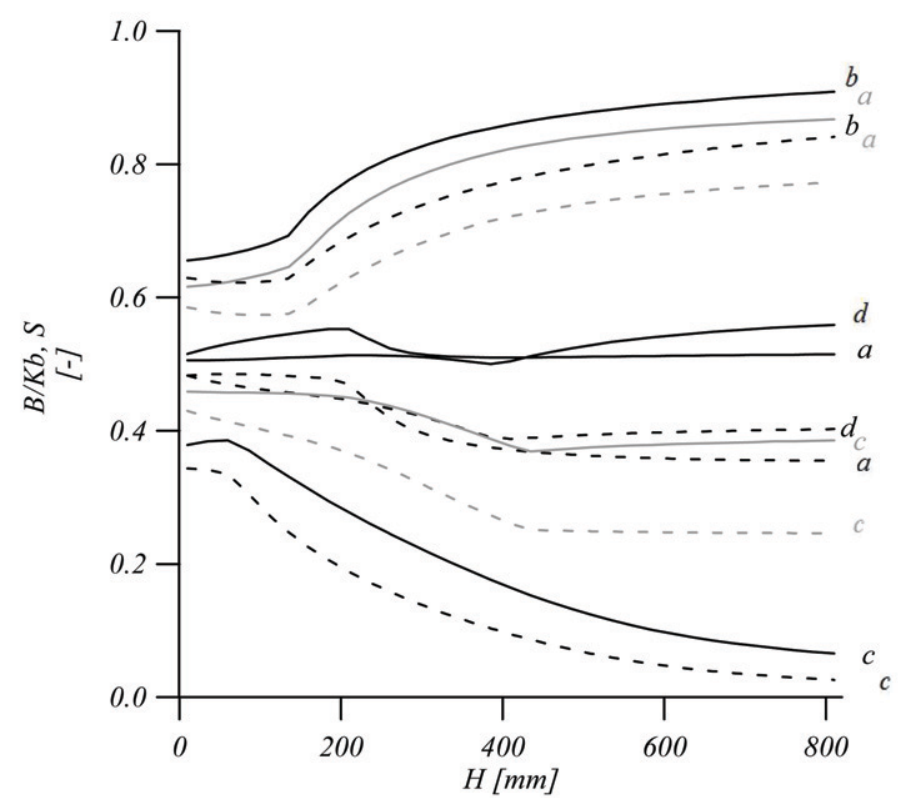

Fig. 15. Model predictions. Average biomass density and soil saturation for different control volume depth $H$. Dashed line: soil saturation; continuous line: dimensionless biomass density. Different scenarios (concerning the soil-water-vegetation interaction) have been simulated. Black lines: positive feedback between vegetation growth and infiltration. Gray lines: wettable soil, and no feedback $g=g(1)$. Curves a and c: low storage capacity due to fast leakage through the root zone toward the water table $n=0.5$. Curves a and b: low evapotranspiration $\mathrm{ET}_{0}=200 \mathrm{~mm} \mathrm{yr}^{-1}$, with high and low leakage $n=0.5$ (a) and $n=5$ (b), respectively. Curves c; d: high evapotranspiration (leading to possible water stress) $\mathrm{ET}_{0}=500 \mathrm{~mm} \mathrm{yr}^{-1}$ with high and low leakage $n=0.5$ (c) and $n=5$ (d), respectively. 
Thus, the "critical" root depth of about $500 \mathrm{~mm}$ (observed at the bare plot of Field 23) may be the signature of vegetation adaptation to climate and/or soil water scarcity.

The vegetation growth indirectly affects locally the average soil saturation and globally the connectivity between the soil moisture paths. Increasing $H$ due to adaptation or physiological characterization turns into an advantage for the vegetation (and to an increase in soil saturation) when no water stress occurs (case b) or when the water stress may be contrasted by a positive feedback between infiltration and biomass growth (cases a and d) despite the formation of a soil surface sealing crust in the absence of vegetation and the either high ET (case d) or high L (case a). When ET and L are both high (case c) deep rooted species are penalized (case c). If the soil surface remains wettable and the conjectured crust does not develop over the bare soil patches (gray lines with no feedback $g(b)=g(1)=0.8)$, moderate and severe water scarcity conditions (cases a and c) turns into more favorable scenarios, leading at least to the conversion of a patchy vegetation cover into a uniform vegetation cover (such as in case a) if the roots can grow deep enough. The fact that the vegetation cover at Field 21 and 23 is different despite the soil texture is similar, may be attributed to species physiology (including the different root depth that affects the annual water balance) and phenology and/or to the vegetationsoil interaction that affects the soil structure, the soil wettability and the vertical connectivity between the soil surface and the deep soil layers. This means that our tentative mechanistic explanation for such different water dynamics at the observed sites may not be unique. Corresponding to a different possible explanation, the expected impact of the local soil vegetation interaction on global soil moisture balance changes.

\section{Conclusions}

This paper presents the results of long-term monitoring and irrigation tests performed on the San Michele experimental farm in Southern Sardinia, an area of semiarid climate where concerns exist about future impacts of possible climatic changes on the already stressed water balance. The collected data allowed us to draw some interesting conclusions.

1. Noninvasive techniques, and particularly soil mapping with electromagnetics and $\gamma$-ray emission, provide data at the scale and resolution necessary to understand the hydrological processes of the topsoil, in their spatial variability. Unlike remote sensing techniques, noninvasive geophysics penetrates the soil subsurface and can effectively image moisture content in the first meter or so, that is, in the active layer where moisture content and vegetation strongly interact.

2. Careful calibration of these noninvasive techniques, in our case on the basis of a controlled irrigation experiment, leads to producing quantitative estimates of moisture content at the scale and resolution needed by large-scale hydrological models.

3. The evidence collected at the San Michele farm using noninvasive techniques point toward a strong interaction between vegetation and soil water dynamics, with important feed backs between biota and water infiltration and exfiltration from the soil.

4. The collected evidence calls for a conceptual model capable of representing the vegetation-soil interaction, and that has simple enough parameterization that can be fulfilled by measurements of a noninvasive nature, available at a large scale. One such key parameter is the thickness of the active layer.

In our experimental site we observed that the growth of vegetation, the associated below ground allocation of biomass and the architecture of root have a significant impact on the soil moisture dynamics. The presence of the roots in the vadose zone has been observed to be crucial in the water balance due to the fact that the below ground biomass affects the soil structure and its response to the hydrologic forcing. We reasonably conjectured that the vegetation that spontaneously grows in the field that was left bare alters the structure of the compact layer that seals the soil surface otherwise. Indeed, the bare soil reacts slowly to rainfall and irrigation and its reaction is confined within the upper soil layers, despite the fact that the vegetation grows deeper roots as compared to the neighbor crop.

By enhancing infiltration, the vegetation grows locally and profits of the increased soil moisture availability and at the same time exploits the scarce water resources creating the conditions that limit its own growth. In many arid sites of the word the mosaic vegetation cover (dense and patchy vegetated patterns within a bare background) represents the reaction of the ecosystem to this complex interplay between soil, biomass and hydrological constrain. We observed a quite uniform, although scattered, vegetation cover that we would attempt to explain on the base of the data collected and the outcome of a minimal model.

Although encouraging, the numerical results presented here shall be considered as preliminary investigations only. Indeed our modeling approach is very simple, as it roughly describes the time variability of the hydrological forcing, the soil characterization and the plant physiology. The model ignores daily time scale processes, and the different dynamics that characterizes the vegetation growth above and below ground. Nevertheless, despite the many simplifying hypothesis, it suggest that accounting for ecohydrological feedback may provide an explanation for some physiological aspect of vegetation growth and soil moisture dynamics.

Geophysics evidenced relevant differences in soil moisture patterns that may be linked to the vegetation growth although our tentative mechanistic explanation for such differences may not be unique.

What reason determines the strong differences in observed soil moisture patterns at different fields certainly deserved deeper investigation to address the main water and land use management issues concerning the water availability and the water quality.

\section{Acknowledgments}


We acknowledge funding from the EU FP7 Collaborative Projects CLIMB ("Climate Induced Changes on the Hydrology of Mediterranean Basins- Reducing Un certainty and Quantifying Risk") and iSOIL ("Linking geophysics, soil science and digital soil mapping").

\section{References}

Abdu, H., D.A. Robinson, M. Seyfried, and S.B. Jones. 2008. Geophysical imaging of watershed subsurface patterns and prediction of soil texture and water holding capacity. Water Resour. Res. 44:W00D18 10.1029/2008WR007043. doi:10.1029/2008WR007043

al Hagrey, S.A., and T. Petersen. 2011. Numerical and experimental mapping of small root zones using optimized surface and borehole resistivity tomography. Geophysics 76(2):G25-G35 10.1190/1.3545067.

Agenzia Regionale per la Protezione dell'Ambiente Sardegna. 2011. Analisi Agro meteorologica e climatologica (Ottobre 2009-Settembre 2010). Cagliari, Italy.

Baudena, M., I. Bevilacqua, D. Canone, S. Ferraris, M. Previati, and A. Provenzale. 2012. Soil water dynamics at a midlatitude test site: Field measurements and box modeling approaches. J. Hydrol. 414-415:329-340.

Bear, J. 1972. Dynamics of fluids in porous media. American Elsevier, New York.

Binley, A. 2011. Free resistivity software. http://www.es.lancs.ac.uk/people/ amb/Freeware/freeware.htm (accessed 4 Dec. 2011).

Binley, A., S. Henry-Poulter and B. Shaw. 1996. Examination of solute transport in an undisturbed soil column using electrical resistance tomography. Water Resour. Res. 32(4): 763-769.</jrn>

Brooks, R.H., and A.T. Corey. 1964. Hydraulic properties of porous media. Hydro. Paper No. 3 Colorado State Univ., Fort Collins.

Brovelli, A., and G. Cassiani. 2011. Combined estimation of effective electrical conductivity and permittivity for soil monitoring. Water Resour. Res. 47:W08510. doi:10.1029/2011WR010487

Cassiani, G., G. Boehm, A. Vesnaver, and R. Nicolich. 1998. A geostatistical framework for incorporating seismic tomography auxiliary data into hydraulic conductivity estimation. J. Hydrol. 206:58-74. doi:10.1016/S0022 1694(98)00084-5.

Cassiani, G., V. Bruno, A. Villa, N. Fusi, A.M. Binley. 2006. A saline tracer test monitored via time-lapse surface electrical resistivity tomography. J. Appl. Geophys. 59:244-259.

Cassiani, G., A. Kemna, A. Villa, and E. Zimmermann. 2009. Spectral induced polarization for the characterization of free-phase hydrocarbon contamination in sediments with low clay content. Near Surf. Geophys. 7:547-562. doi:10.3997/1873-0604.2009028.

Cody, M.L. 1986. Roots in plant ecology. Trends Ecol. Evol. 1:76-78. doi:10.1016/0169-5347(86)90022-4

Comas, X., L. Slater, and A. Reeve. 2004. Geophysical evidence for peat basin morphology and stratigraphic controls on vegetation observed in a northern peatland. J. Hydrol. 295:173-184. doi:10.1016/j.jhydrol.2004.03.008.

Corwin, D.L., and S.M. Lesch. 2005. Characterizing soil spatial variability with apparent soil electrical conductivity: I. Survey protocols. Comput. Electron. Agric. 46:103-133. doi:10.1016/j.compag.2004.11.002.

Day-Lewis, F.D., K. Singha, and A.M. Binley. 2005. Applying petrophysical models to radar travel time and electrical resistivity tomograms: Resolution-dependent limitations. J. Geophys. Res. 110:B08206. doi:10.1029/2004JB003569.

Deiana R., G. Cassiani, A. Villa, A. Bagliani and V. Bruno. 2008. Model calibration of a water injection test in the vadose zone of the Po River plain using GPR cross-hole data. Vadose Zone J. 7:215-226. doi:10.2136/vzj2006.0137.

Eagleson, P.S. 2002. Ecohydrology: Darwinian expression of vegetation form and function. Cambridge Univ. Press, New York.

Flury, M., H. Flühler, W.A. Jury, and J. Leuenberger. 1994. Susceptibility of soils to preferential flow of water: A field study. Water Resour. Res. 30(7):19451954 doi:10.1029/94WR00871.

Guswa, A.J. 2008. The influence of climate on root depth: A carbon cost benefit analysis. Water Resour. Res. 44:W02427. doi:10.1029/2007WR006384.

Guswa, A.J. 2010. Effect of plant uptake strategy on the water-optimal root depth. Water Resour. Res. 46:W09601. doi:10.1029/2010WR009122.

HilleRisLambers, R., M. Rietkerk, F. van den Bosch, H.H.T. Prins, and H. de Kroon. 2001. Vegetation pattern formation in semi-arid grazing systems. Ecology 82:50-61. doi:10.1890/0012-9658(2001)082[0050:VPFISA]2.0.CO;2

Huxman, T.E., B.P. Wilcox, D.D. Breshears, R.L. Scott, K.A. Snyder, E.E. Small, K. Hultine, W.T. Pockman, and R.B. Jackson. 2005. Ecohydrological implication of woody plant encroachment. Ecology 86:308-319. doi:10.1890/03-0583.

Jackson, R.B., E.G. Jobbagy, and M.D. Nosetto. 2009. Ecohydrology bearingsInvited commentary. Ecohydrology in a human-dominated landscape. Ecohydrology 2:383-389. doi:10.1002/eco.81.

Javaux, M., T. Schroder, J. Vanderborght, and H. Vereecken. 2008. Use of a three-dimensional detailed modeling approach for predicting root water uptake. Vadose Zone J. 7:1079-1088. doi:10.2136/vzj2007.0115

Jung, W.K., N.R. Kitchen, K.A. Sudduth, R.J. Kremer, and P.P. Motavalli. 2005. Relationship of apparent soil electrical conductivity to claypan soil properties. Soil Sci. Soc. Am. J. 69:883-892. doi:10.2136/sssaj2004.0202.
Kachanoski, R.G., E.G. Gregorich, and I.J. Van Wesenbeeck. 1988. Estimating spatial variations of soil water content using non-contacting electromagnetic inductive methods. Can. J. Soil Sci. 68:715-722. doi:10.4141/cjss88-069.

Kim, C.P., J.N.M. Stricker, and P.J.J.F. Torfs. 1996. An analytical framework for the water budget of the unsaturated zone. Water Resour. Res. 32(12):34753484. doi:10.1029/95WR02667.

Lieth, H., and R.H. Whittaker. 1975. Primary productivity of the biosphere. Ecol. Stud., Vol. 14. Springer-Verlag, New York.

Ludwig, R., A. Soddu, R. Duttmann, N. Baghdadi, S. Benabdallah, R. Deidda, et al. 2010. Climate-induced changes on the hydrology of Mediterranean basins-A research concept to reduce uncertainty and quantify risk. Fresenius Environ. Bull. 19(10A):2379-2384.

Ma, R., A. McBratney, B. Whelan, B. Minasny, and M. Short. 2011. Comparing temperature correction models for soil electrical conductivity measurement. Precis. Agric. 12:55-66. doi:10.1007/s11119-009-9156-7.

Michot, D., Y. Benderitter, A. Dorigny, B. Nicoullaud, D. King, and A. Tabbagh. 2003. Spatial and temporal monitoring of soil water content with an irrigated corn crop cover using surface electrical resistivity tomography. Water Resour. Res. 39(5):1138. doi:10.1029/2002WR001581.

Milly, P.C.D. 1993. An analytic solution of the stochastic storage problem applicable to soil water. Water Resour. Res. 29(11):3755-3758 doi:10.1029/93WR01934

Monego, M., G. Cassiani, R. Deiana, M. Putti, G. Passadore, and L. Altissimo. 2010. Tracer test in a shallow heterogeneous aquifer monitored via timelapse surface ERT. Geophysics 75(4):WA61-WA73. doi:10.1190/1.3474601.

Newman, B.D., B.P. Wilcox, S.R. Archer, D.D. Breshears, C.N. Dahm, C.J. Duffy, et al. 2006. Ecohydrology of water-limited environments: A scientific vision. Water Resour. Res. 42:W06302. doi:10.1029/2005WR004141.

Nuttle, W.K. 2002. Ecohydrology's past and future in focus. Eos Trans. AGU 83:205. doi:10.1029/2002EO000138.

Porporato, A., E. Daly, and I. Rodriguez-Iturbe. 2004. Soil water balance and ecosystem response to climate change. Am. Nat. 164:625-632. doi:10.1086/424970.

Richards, L.A. 1931. Capillary conduction of liquids through porous mediums Physics 1(5):318-333. doi:10.1063/1.1745010.

Rietkerk, M. M.C. Boerlijst, F. van Langevelde, R. HilleRisLambers, J. van de Koppel, and L. Kumar. 2002. Self-organization of vegetation in arid ecosystem. Am. Nat. 160:524-530. doi:10.1086/342078.

Robinson, D.A., A. Binley, N. Crook, F. Day-Lewis, P.T. Ferré, V.J.S. Grauch, et al. 2008. Advancing process-based watershed hydrological research using near-surface geophysics: A vision for, and review of, electrical and magnetic geophysical methods. Hydrol. Processes 22:3604-3635. doi:10.1002/ hyp.6963.

Robinson, D.A., I. Lebron, B. Kocar, K. Phan, M. Sampson, N. Crook, et al. 2009 Time-lapse geophysical imaging of soil moisture dynamics in tropical deltaic soils: An aid to interpreting hydrological and geochemical processes. Water Resour. Res. 45:W00D32. doi:10.1029/2008WR006984

Sheets, K.R., and J.M.H. Hendrickx. 1995. Noninvasive soil water content measurement using electromagnetic induction. Water Resour. Res. 31:24012409. doi:10.1029/95WR01949.

Singha, K., and S.M. Gorelick. 2005. Saline tracer visualized with three-dimensional electrical resistivity tomography: Field-scale spatial moment analysis. Water Resour. Res. 41:W05023. doi:10.1029/2004WR003460.

Strobbia, C., and G. Cassiani. 2007. Multi-layer GPR guided waves in shallow soil layers for the estimation of soil water content. Geophysics 72(4):J17J29. doi:10.1190/1.2716374.

Triantafilis, J., and S.M. Lesch. 2005. Mapping clay content variation using electromagnetic induction techniques. Comput. Electron. Agric. 46:203-237. doi:10.1016/j.compag.2004.11.006

Ursino, N. 2005. The influence of soil properties on the formation of unstable vegetation patterns on hillsides of semiarid catchments. Adv. Water Resour. 28:956-963. doi:10.1016/j.advwatres.2005.02.009

Ursino, N. 2007. Modeling banded vegetation patterns in semiarid regions: Interdependence between biomass growth rate and relevant hydrological processes. Water Resour. Res. 43:W04412. doi:10.1029/2006WR005292.

Ursino, N. 2009. Above and below ground biomass patterns in arid lands. Ecol. Modell. 220:1411-1418. doi:10.1016/j.ecolmodel.2009.02.023.

Vereecken, H., A. Binley, G. Cassiani, I. Kharkhordin, A. Revil, and K. Titov (eds). 2006. Applied hydrogeophysics. Springer-Verlag, Berlin.

Verhulst, P.F. 1838. Notice sur la loi que la populationsuit dans son accroissement. Corr. Math. Phys. 10:113-117.

Waxman, M.H., and L.J.M. Smits. 1968. Electrical conductivities in oil-bearing shaly sands. Soc. Pet. Eng. J. 8:107-122.

Werban, U., S.A. al Hagrey, and W. Rabbel. 2008. Monitoring of root-zone water content in the laboratory by 2D geoelectrical tomography. J. Plant Nutr. Soil Sci. 171(6):927-935. doi:10.1002/jpln.200700145.

Werban, U., T. Behrens, G. Cassiani, and P. Dietrich. 2010. iSOIL: An EU project to integrate geophysics, digital soil mapping, and soil science. In: R.A. Viscarra Rossel, A. McBratney, and B. Minasny, editors, Proximal soil sensing. Progress in Soil Sci. 1. Springer, Berlin. p. 103-110. doi:10.1007/978-90-481-8859-8_8. 